\title{
The Boreal-Summer Intraseasonal Oscillations Simulated in a Hybrid Coupled Atmosphere-Ocean Model*
}

\author{
Xiouhua Fu AND Bin Wang \\ International Pacific Research Center, School of Ocean and Earth Science and Technology, University of Hawaii at Manoa, \\ Honolulu, Hawaii
}

(Manuscript received 9 September 2003, in final form 15 May 2004)

ABSTRACT

The boreal-summer intraseasonal oscillation (BSISO) simulated by an atmosphere-ocean coupled model is validated with the long-term observations [Climate Prediction Center (CPC) Merged Analysis of Precipitation (CMAP) rainfall, ECMWF analysis, and Reynolds' SST]. This validation focuses on the three-dimensional water vapor cycle associated with the BSISO and its interaction with underlying sea surface. The advantages of a coupled approach over stand-alone atmospheric approaches on the simulation of the BSISO are revealed through an intercomparison between a coupled run and two atmosphere-only runs.

This coupled model produces a BSISO that mimics the one presented in the observations over the Asiawestern Pacific region. The similarities with the observations include 1) the coherent spatiotemporal evolutions of rainfall, surface winds, and SST associated with the BSISO; 2) the intensity and period (or speed) of the northward-propagating BSISO; and 3) the tropospheric moistening (or drying) and overturning circulations of the BSISO. However, the simulated tropospheric moisture fluctuations in the extreme phases (both wet and dry) are larger than those in the ECMWF analysis. The simulated sea surface cooling during the wet phase is weaker than the observed cooling. Better representations of the interaction between convection and boundary layer in the GCM and including salinity effects in the ocean model are expected to further improve the simulation of the BSISO.

The intercomparison between a coupled run and two atmospheric runs suggests that the air-sea coupled system is the ultimate tool needed to realistically simulate the BSISO. Though the major characteristics of the BSISO are very likely determined by the internal atmospheric dynamics, the correct interaction between the internal dynamics and underlying sea surface can only be sustained by a coupled system. The atmosphere-only approach, when forced with high-frequency (e.g., daily) SST, introduces an erroneous boundary interference on the internal dynamics associated with the BSISO. The implications for the predictability of the BSISO are discussed.

\section{Introduction}

Intraseasonal oscillation (ISO) is an essential component of the Asia-western Pacific summer monsoon system (Krishnamurti 1985; Webster et al. 1998; Lau et al. 2000). The rainfall variance associated with the ISO exceeds considerably the variance associated with interannual fluctuations in the monsoon area (Waliser et al. 2003a). Regionally, these intraseasonal oscillations strongly regulate the onset (retreat) and active (break) spells of the Asian summer monsoon (e.g., Yasunari 1979; Lau and Chan 1986; Kang et al. 1999; Sengupta et al. 2001; Wu et al. 2002; Fu et al. 2002). Through

\footnotetext{
* School of Ocean and Earth Science and Technology Contribution Number 6429 and International Pacific Research Center Contribution Number 282.

Corresponding author address: Dr. Xiouhua Fu, IPRC, SOEST, University of Hawaii at Manoa, 1680 East-West Road, POST Bldg. 401, Honolulu, HI 96822.

E-mail: xfu@ soest.hawaii.edu
}

teleconnection, the ISO that originates in the Asia-western Pacific region modulates the subseasonal rainfall variability in the extratropical region (Kawamura et al. 1996), even over North America (Mo 2000). Better understanding and simulation of the ISO are expected to extend our forecasting capability with a time advance of about one month (Krishnamurti et al. 1992; Waliser et al. 2003b), which bridges the gap between weather forecasting $(\sim$ one week $)$ and seasonal climate prediction $(\sim$ a few months).

State-of-the-art atmospheric general circulation models (GCMs) have shown some successes in simulating the intraseasonal oscillations (Slingo et al. 1996; Sperber et al. 1997). Many models are able to produce robust eastward-propagating Madden-Julian oscillations (MJOs; Madden and Julian 1971) gauged with planetary-scale upper-layer velocity potential variability. Most GCMs, however, cannot yet realistically simulate the BSISO associated with the Asia-western Pacific summer monsoon in terms of its intensity and propagation (Waliser et al. 2003a). All 10 GCMs participating 
in the Climate Variability and Predictability program (CLIVAR)/Asian-Australian monsoon intercomparison project (Kang et al. 2002) considerably underestimate the intraseasonal variability near the equatorial Indian Ocean, where the observed ISO has its largest amplitude year-round and a favorable region of amplification (Wang and Rui 1990). Though most of these GCMs produce strong summer-mean Indian monsoon rainfall, the simulated northward-propagating intraseasonal oscillations remain systematically weaker than the observed (Waliser et al. 2003a). This finding implies that reasonable simulation of summer-mean Indian monsoon rainfall (with a dominant rainbelt around $15^{\circ} \mathrm{N}$ ) does not necessarily yield a successful simulation of the borealsummer ISO (BSISO) with its origin and an action center near the equatorial Indian Ocean and preferential northeastward propagation in the Asia-western Pacific region (Yasunari 1979; Lau and Chan 1986; Wang and Rui 1990).

Intraseasonal oscillation has its roots in internal atmospheric dynamics (Chang 1977; Lau and Peng 1987; Wang 1988; Blade and Hartmann 1993; Hu and Randall 1994; Neelin and Yu 1994; Raymond 2001, among others). This has been supported by the fact that an atmosphere-only model is able to produce an oscillation similar to the MJO. On the other hand, Wang and Xie (1998) proposed that warm-pool air-sea coupling is able to contribute to the growth and maintenance of an MJOlike mode. In fact, significant SST fluctuations associated with the ISO in the tropical Indian and western Pacific Oceans have long been documented by Krishnamurti et al. (1988). With the data from the Tropical Ocean Global Atmosphere Coupled Ocean-Atmosphere Response Experiment (TOGA COARE; Webster and Lukas 1992), Zhang (1996) also documented the coherent relationships between MJO and underlying SST fluctuations. These findings raised an important question: Are the intraseasonal SST fluctuations just passive responses to the atmospheric ISO or do the SST fluctuations significantly feed back to the ISO? A number of modeling studies (Flatau et al. 1997; Waliser et al. 1999; Hendon 2000; Kemball-Cook et al. 2002; Inness and Slingo 2003; Fu et al. 2003; Zheng et al. 2004; Rajendran et al. 2004) have attempted to address this question. Almost all these studies (except Hendon 2000) have shown that air-sea interaction improves both the MJO in boreal winter and the BSISO in boreal summer in terms of their intensity, propagation, and seasonality. With a series of small-perturbation experiments, $\mathrm{Fu}$ and Wang (2004) further showed that two different ISO solutions actually exist in the atmosphere-ocean coupled system and the forced atmosphere-only system, respectively. The solution in the coupled system is closer to the observations. The exception of Hendon (2000) is largely attributed to the failure of the model to simulate a reasonable surface latent heat flux associated with the model MJO. However, the exception of Hendon (2000) reminds us that air-sea coupling is not a panacea for all the modeling problems of ISO, but may be viewed as a significant piece in the puzzle of realistically simulating ISO. The representations of other pieces in the puzzle, for example, cumulus parameterization (Tokioka et al. 1988; Wang and Schlesinger 1999; Maloney and Hartmann 2001), cloud-radiation interaction (Lee et al. 2001), boundary layer processes (Wang 1988), and land surface processes (Webster 1983), are also important in order to advance our capability of simulating ISO with general circulation models.

Using a hybrid coupled model (ECHAM4 GCM with the Wang-Li-Fu intermediate ocean model), Fu et al. (2003) found that air-sea interaction significantly increases the intensity of the northward-propagating BSISO (NPISO) over the Indian sector. Forcing GCM with daily mean SST produces a stronger NPISO compared to that forced by monthly mean SST [Atmospheric Model Intercomparison Project (AMIP)-type], but is still unable to reproduce the NPISO intensity in the coupled model. The improved simulation of the NPISO in this hybrid-coupled model enables a further comprehensive model validation with the available observations. We address the following three questions in this study: 1) In what aspects does this hybrid-coupled model yield a reasonable simulation of the BSISO over the tropical Asia-western Pacific region? 2) What are the obvious discrepancies with the available observations and the possible causes? 3) To what degree can air-sea interaction change the characteristics of the BSISO simulated in the atmosphere-only model? We expect that this study will lead us to better understand the major physical processes controlling the BSISO in the model and shed light on the directions to further improve the model.

This validation focuses on the water vapor cycle of the BSISO (Myers and Waliser 2003) and its interaction with underlying sea surface, in contrast to previous approaches (Rui and Wang 1990; Hendon and Salby 1994; Slingo et al. 1996) that measured ISO with outgoing longwave radiation (OLR) and two-layer dynamical fields (e.g., velocity potential and zonal winds) at 850and 200-hPa surfaces. The present approach is based on the following assumptions: 1) an adequate representation of tropospheric moistening associated with atmospheric convection is important to the initiation and maintenance of ISO in GCMs (Tompkins 2001; Grabowski 2003) and 2) air-sea interaction plays an important role on realistic simulation of ISO (Flatau et al. 1997; Waliser et al. 1999).

This paper is structured as follows: The model and data are introduced in section 2. The BSISO simulated in the coupled model is validated with available observations and compared to the simulations of atmosphereonly runs in the following two sections. In section 3, the comparisons are devoted to the horizontal patterns and temporal evolutions in the entire tropical Asia-western Pacific region. Section 4 focuses on the NPISO in the Indian Ocean sector. In the last section, we sum- 
marize our results and discuss the model caveats and future studies.

\section{Model and data}

\section{a. Model description and experimental designs}

\section{1) The COupled MOdel}

The atmospheric component of this coupled model is the ECHAM4 GCM (Roeckner et al. 1996). Its horizontal resolution is about $3.75^{\circ}$ in both longitude and latitude (a T30 version), with 19 vertical levels extending from the surface to $10 \mathrm{hPa}$. The mass flux scheme of Tiedtke (1989) is used to represent the deep, shallow, and midlevel convection. A CAPE closure scheme has been implemented by Nordeng (1994) to replace the original moisture-convergence closure. The ocean component of the coupled model is a 2.5-layer tropical upper-ocean model with a horizontal resolution of $2^{\circ}$ longitude by $1^{\circ}$ latitude. It was originally developed by Wang et al. (1995) and improved by Fu and Wang (2001) (hereafter the WLF ocean model). The WLF ocean model combines the mixed-layer thermodynamics of Gaspar (1988) and the upper-ocean dynamics of McCreary and $\mathrm{Yu}$ (1992). The ocean model is able to simulate realistic annual cycles of SST, upper-ocean currents, and mixedlayer thickness in the tropical Pacific (Fu and Wang 2001). The ECHAM4 GCM and WLF ocean model are coupled in the tropical Indian and Pacific Oceans. Outside these regions, the underlying SST is specified as the climatological monthly mean SST averaged for 16 yr (1979-94) from the boundary conditions of AMIP II experiments (Taylor et al. 2000). In the central-eastern Pacific (east of the date line), the model SST is relaxed toward the observations in order to avoid excessive westward extension of the Pacific cold tongue (Fu et al. 2002). The atmospheric component exchanges information with the ocean component once per day. The initial atmospheric state is taken from the European Centre for Medium-Range Weather Forecasts (ECMWF) analysis on 1 January 1988. The initial oceanic state is the January state after a 10 -yr integration of the stand-alone ocean model forced by observed climatological surface winds and heat fluxes. The coupled model is integrated for $16 \mathrm{yr}$, and the last $10 \mathrm{yr}$ of the run are used in the analyses reported below. We refer to this simulation as the "coupled run."

\section{2) StAnd-ALONE ATMOSPHERIC EXPERIMENTS}

To assess the impacts of air-sea coupling and intraseasonal SST fluctuations on the characteristics of the BSISO, two more sensitivity experiments are conducted with the stand-alone ECHAM4 GCM. In the "mean" experiment (AMIP-type), the climatological monthly mean SST from the coupled run is used to force the model, and the initial conditions are the same as those for the coupled run. It is integrated for $16 \mathrm{yr}$, and the output from the last $10 \mathrm{yr}$ is used in the analyses. In the "daily" experiment, the SST forcing is daily mean SST from the last $10 \mathrm{yr}$ of the coupled run, and the initial conditions are unchanged.

\section{b. Data and methods}

The data used to validate the model are from the ECMWF analysis (three-dimensional atmospheric fields and surface heat fluxes), Climate Prediction Center (CPC) Merged Analysis of Precipitation rainfall (Xie and Arkin 1997), and Reynolds' SST (Reynolds and Smith 1994). All data cover the 10-yr period from 1991 to 2000. The temporal resolutions for ECMWF analysis, CMAP, and Reynolds' data are daily, pentad, and weekly, respectively. In the following analyses, all data are averaged or interpolated into pentad-mean data.

Because almost all the above datasets are not in situ data, they are actually proxies of the observations. Recently, two field campaigns, the Joint Air-Sea Monsoon Interaction Experiment (JASMINE; Webster et al. 2002) and the Bay of Bengal Monsoon Experiment (BOBMEX; Bhat et al. 2001), have been carried out to investigate the BSISO in the Indian Ocean. These observations facilitate air-sea coupled process studies. However, the limited numbers of the cases that occur during the campaign periods are too few to construct statistical evolutions of the BSISO in the Asia-western Pacific sector. We are also aware that the rainfall and SST data from the Tropical Rainfall Measuring Mission (TRMM) Microwave Imager (TMI; Vecchi and Harrison 2002) are available for recent years. A preliminary comparison between TMI data and the historical data (CMAP and Reynolds) suggests that they are comparable during recent years in terms of the large-scale variations associated with the BSISO (figure not shown). Concerning the short period of the available TMI data, we decided to use those long-term proxies to surrogate the observed BSISO in this study. Because those proxy data used here are from different sources, the coherent evolutions among CMAP rainfall, Reynolds' SST, and ECMWF analysis of atmospheric variables and surface heat fluxes suggest the usefulness of these proxies. These proxy data will be referred as "observations" in the remaining text.

In order to evaluate the simulated BSISO against the observations as objectively as possible, several complementary methods for ISO analysis are applied. The lag regression is used to document the spatiotemporal evolutions of precipitation, surface winds, and SST associated with the BSISO. The wavenumber-frequency analysis (Hayashi 1982; Teng and Wang 2003; Fu et al. 2003 ) is used to quantify the northward- and southwardpropagating disturbances in the Indian sector. Traditional composite analysis is also used to construct the vertical moisture (circulation) structures associated with the NPISO. Except for the wavenumber-frequency analysis (in which unfiltered rainfall data are used), all other 
analyses use the filtered 20-70-day variables (Rui and Wang 1990).

\section{The BSISO in the Asia-Pacific sector}

\section{a. Mean state and BSISO action centers}

Figure 1 compares rainfall and zonal wind shear $(850-200 \mathrm{hPa})$ from the observations, the mean run and the coupled run in boreal summer [June-July-AugustSeptember (JJAS)]. Both model solutions (Figs. 1b and 1c) capture the major rainfall areas and easterly shears in the observations (Fig. 1a), but also have some systematic errors. In the Indian sector, both runs reproduce the observed double rainbelts: one near the equator and the other around $15^{\circ} \mathrm{N}$. The rainfall in the eastern Arabian Sea and Bay of Bengal is underestimated, thus yielding a weaker vertical shear in the Indian Ocean. In spite of these biases, the simulations are relatively better than most GCMs participating in the AMIP monsoon intercomparison project (Gadgil and Sajani 1998) and the CLIVAR/monsoon intercomparison project (Kang et al. 2002), in which only a few GCMs are able to produce two convergence zones in the Indian sector. Many current GCMs tend to produce an excessively strong rainbelt near $15^{\circ} \mathrm{N}$ (Kang et al. 2002) with the equatorial rainbelt significantly weakened or totally suppressed. The lack of active convection near the equatorial Indian Ocean is probably one reason why the NPISOs in these GCMs are systematically weak (Waliser et al. 2003a). In the western North Pacific (WNP), the simulated rainfall (Figs. $1 \mathrm{~b}$ and 1c) is considerably smaller than the observed (Fig. 1a), which is probably associated with the erroneously strong rainfall over the Philippine Islands. The reason for this systematic error of ECHAM4 GCM is unclear (Roeckner et al. 1996). The models (Figs. 1b and 1c) also tend to produce erroneous double ITCZs in the western Pacific rather than a dominant northern one in the observations (Fig. 1a), probably a result of the cold bias in the coupled SST (Fig. 1c in Fu et al. 2003). The summer-mean rainfall and vertical shear in the daily run (forced by the daily mean SST of the coupled run) is similar to those in the mean and coupled runs (Figs. 1b and 1c).

Figure 2 presents the standard deviation of tropical intraseasonal rainfall in boreal summer over the Asiawestern Pacific sector from the CMAP, the mean run, and the coupled run, respectively. In the observations (Fig. 2a), there are five active regions of the BSISO: the eastern Arabian Sea, Bay of Bengal, equatorial Indian Ocean, South China Sea, and the WNP. In the atmosphere-only run (Fig. 2b), the BSISO activities in the Bay of Bengal, South China Sea, and eastern Arabian Sea are considerably weaker than in the observations. Note that in the $10 \mathrm{GCMs}$ evaluated by Waliser et al. (2003a), nearly all models missed the active ISO center over the equatorial Indian Ocean, but ECHAM4 produces significant intraseasonal variability there. It is probably due to the large summer-mean convection in this area (Roeckner et al. 1996; Fu et al. 2002). Compared to the mean run (Fig. 2b), the ISO variance is significantly increased in the coupled run (Fig. 2c) over the equatorial Indian Ocean, Bay of Bengal, South China Sea, and eastern Arabian Sea (the result of the daily run is stronger than the mean run, but weaker than the coupled run; see Fig. 7 in this paper or Fig. 4 in Fu et al. 2003). Because the monthly mean SST of the coupled run is used to force the atmospheric model in the mean run, the resultant mean states in the two simulations (Figs. 1b and 1c) are very similar (see also Waliser et al. 1999). However, the differences in the ISO variability between the mean run (Fig. 2b) and the coupled run (Fig. 2c) are noticeable because of the impacts of airsea coupling. In the coupled run the ISO intensity is significantly enhanced over the equatorial Indian Ocean, Bay of Bengal, and South China Sea. As in the summermean states (Figs. $1 \mathrm{~b}$ and 1c), an erroneously strong ISO action center over the Philippine Islands is produced in both the coupled run and the atmosphere-only run, which may be responsible for the weak ISO in the WNP (Figs. 2b and 2c).

\section{b. Coherent spatiotemporal evolutions}

\section{1) Coupled model Versus observations}

The cyclic evolutions of the BSISO are revealed with a regression analysis. The reference time series is the filtered rainfall averaged in the eastern Indian Ocean $\left(5^{\circ} \mathrm{S}-5^{\circ} \mathrm{N}, 80^{\circ}-100^{\circ} \mathrm{E}\right)$ where large ISO variability occurs in both the observations and the simulations (Fig. 2 ). This region was also identified as an amplification and initiation region for the BSISO (Wang and Rui 1990; Kemball-Cook and Wang 2001). It is found that the CMAP rainfall, ECMWF surface winds, and underlying Reynolds' SST associated with the BSISO evolve coherently in the Asia-western Pacific sector (Fig. 3).

Figures 3 and 4 compare the spatiotemporal evolutions of rainfall, surface wind, and SST fluctuations associated with the BSISO obtained from the observations and the coupled run. Five pentads prior to the ISO rainfall reaching the maximum in the reference region $\left(5^{\circ} \mathrm{S}-\right.$ $5^{\circ} \mathrm{N}, 80^{\circ}-100^{\circ} \mathrm{E}$ ), a negative rainfall anomaly appears in the equatorial Indian Ocean (Fig. 3a). An anticyclonic Rossby wave response to the anomalous atmospheric cooling enhances southwesterly monsoons. A positive rainfall belt forms around $15^{\circ} \mathrm{N}$, extending eastward from the Arabian Sea to the WNP. This phase corresponds to the active spell of the Indian monsoon. The enhanced convection and surface winds are cooling the northern Indian Ocean and the western Pacific. The coupled model (Fig. 4a) captures most of these features, except that the positive rainfall anomalies in the WNP and Indian subcontinent are weaker than the observations, and a positive SST anomaly starts to develop in 
(a) Rainfall/(U850-U200) in Boreal Summer

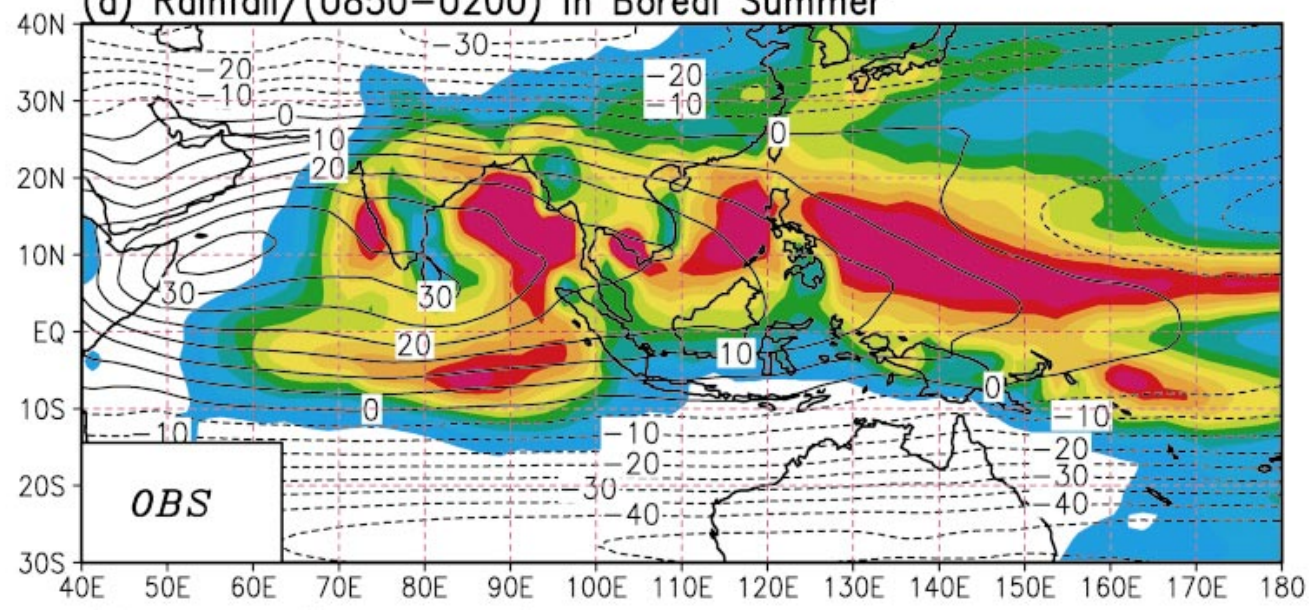

(b) Rainfall/(U850-U200) in Boreal Summer

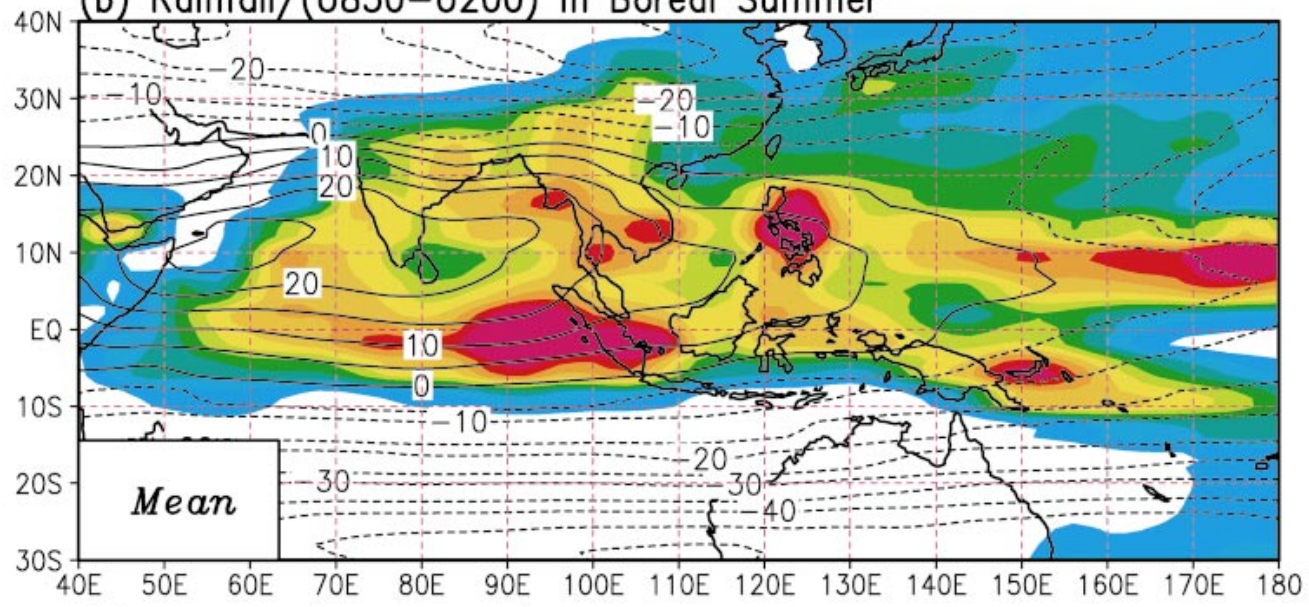

(c) Rainfall/(U850-U200) in Boreal Summer
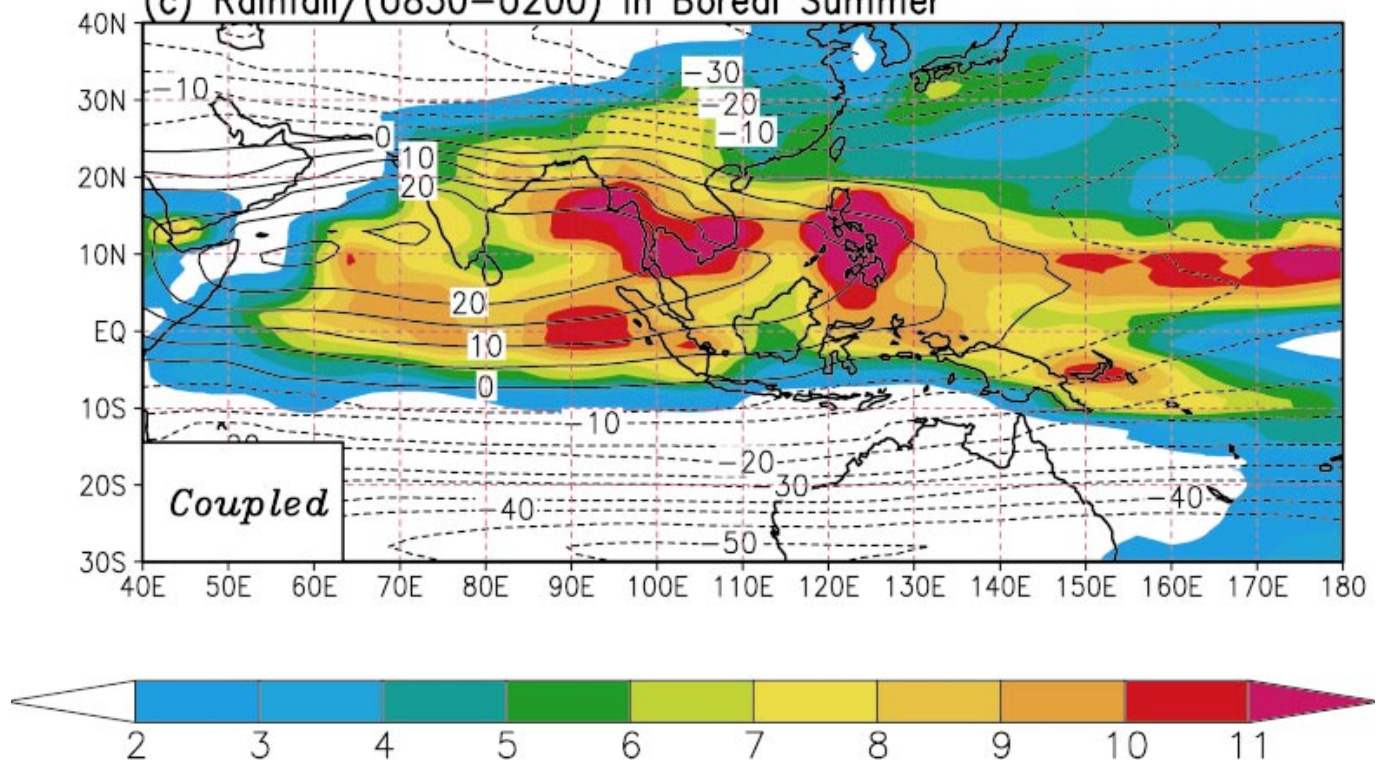

FIG. 1. Rainfall rate (mm day ${ }^{-1}$; shaded) and zonal wind shear $(850-200 \mathrm{hPa}$; contours) averaged in boreal summer (JJAS) from (a) the observations (CMAP rainfall and winds from ECMWF analysis), (b) the atmosphere-only run forced by the monthly mean SST (the mean run), and (c) the coupled run. The contour interval is $5 \mathrm{~m} \mathrm{~s}^{-1}$. 
(a) ISO Rainfall STD in Boreal Summer

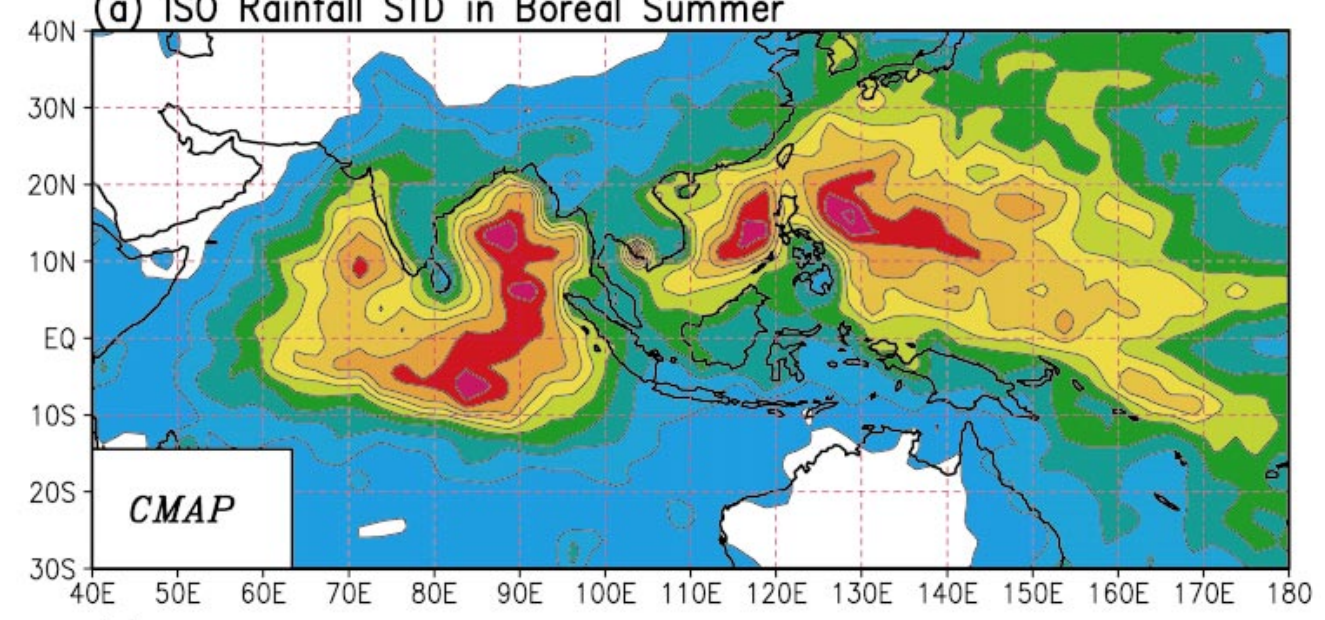

(b) ISO Rainfall STD in Boreal Summer

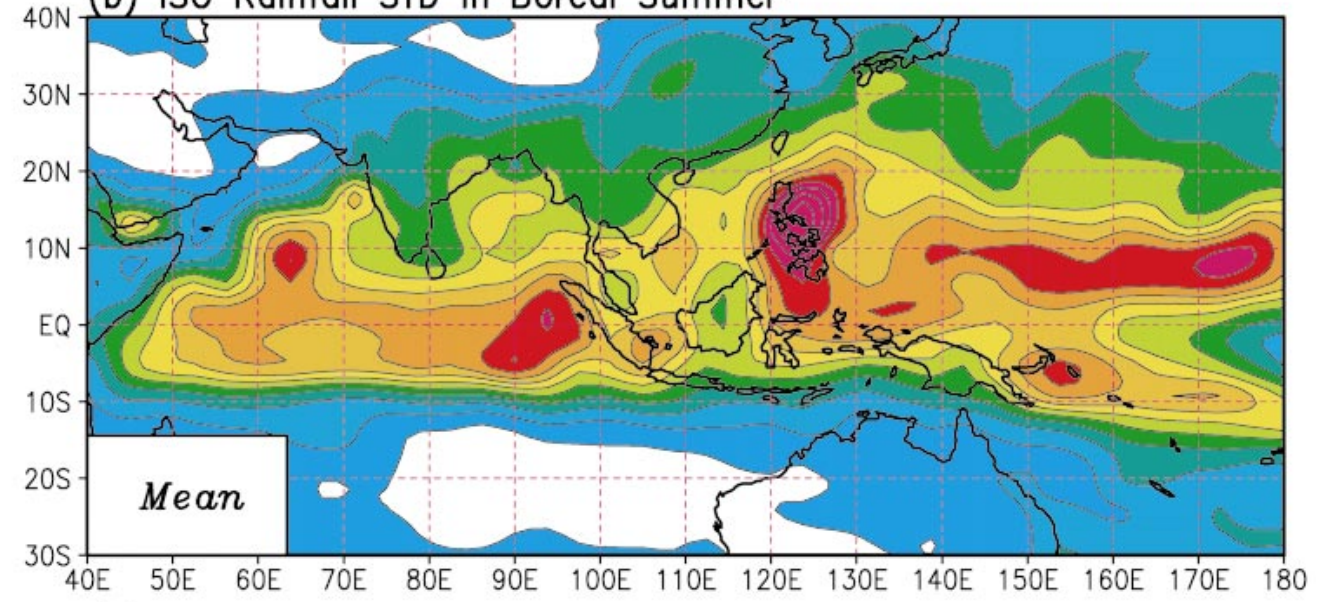

${ }_{40 N}$ (c) ISO Rainfall STD in Boreal Summer
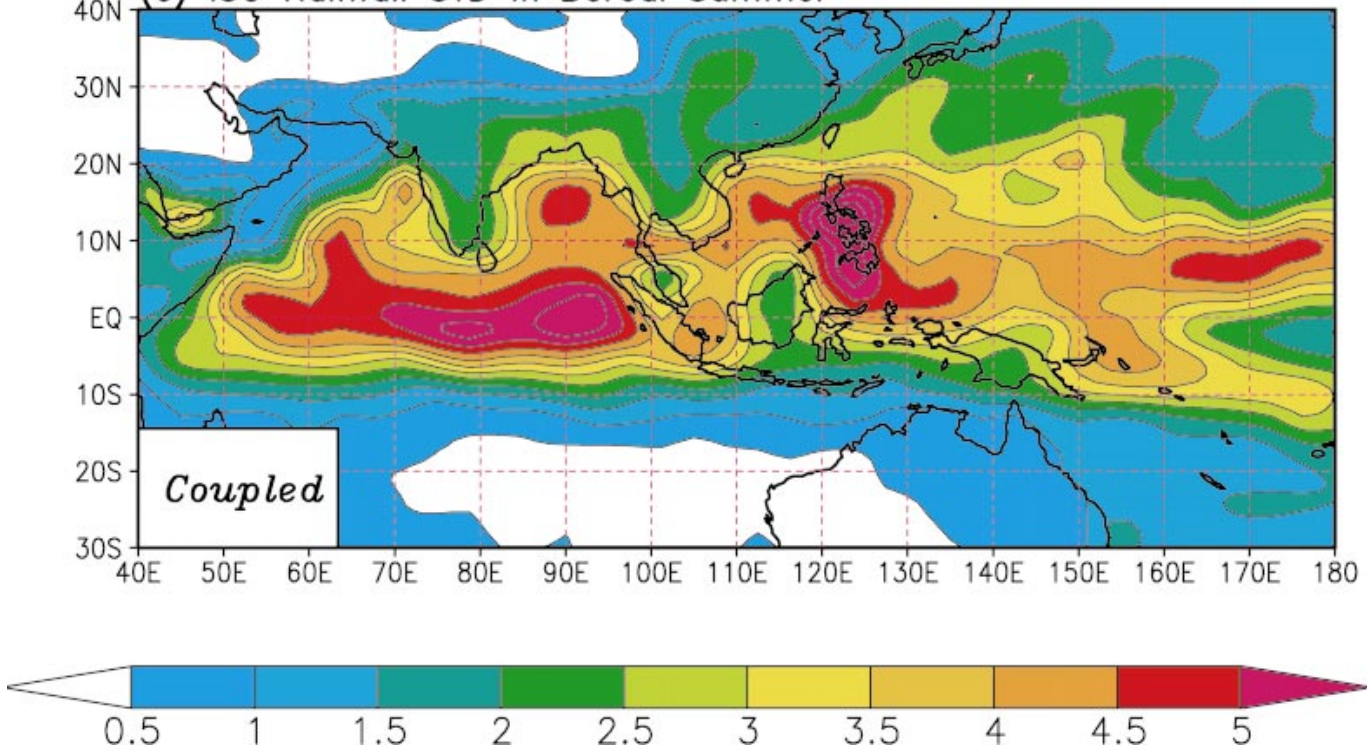

FIG. 2. Standard deviation of intraseasonal rainfall rate $\left(\mathrm{mm}^{-1 a y}{ }^{-1}\right.$; shaded) from (a) the observations (CMAP rainfall), (b) the atmosphere-only run forced by the monthly mean SST, and (c) the coupled run. 


\section{CMAP-ECMWF-SST}
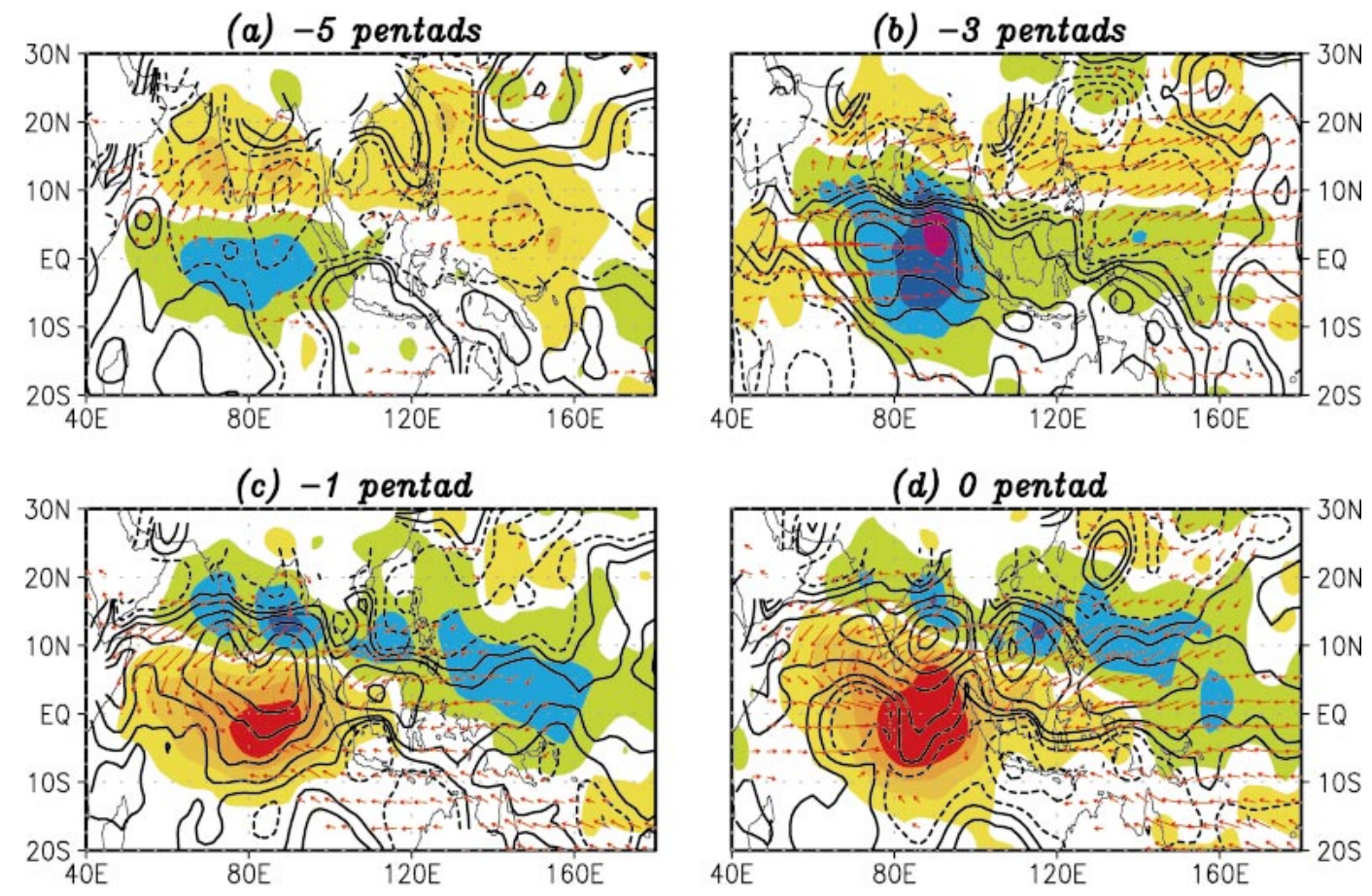

(d) 0 pentad

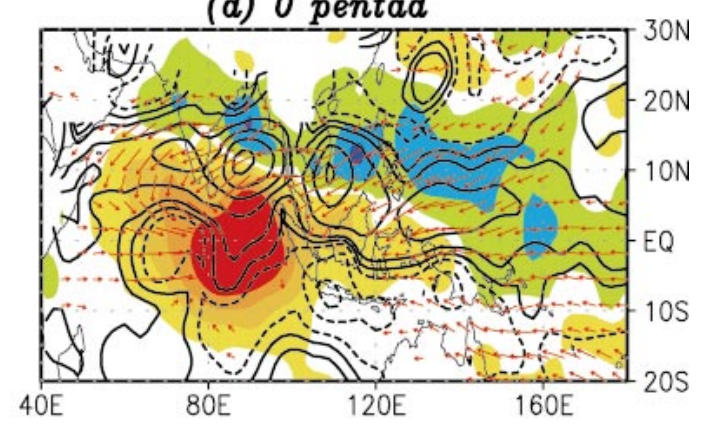

(e) +1 pentads
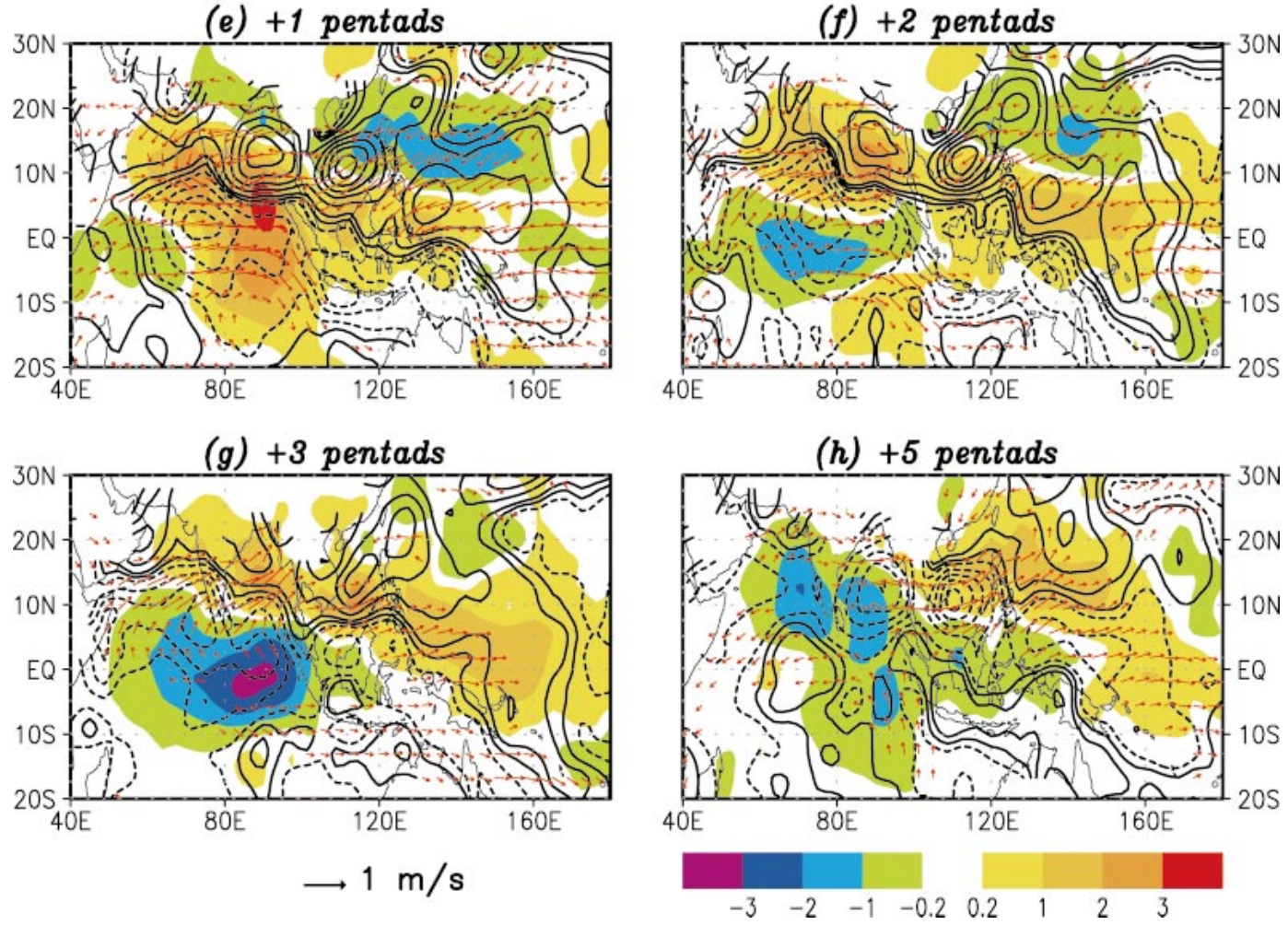

FIG. 3. Regressed rainfall (mm day ${ }^{-1}$; shaded), surface winds $\left(\mathrm{m} \mathrm{s}^{-1}\right.$; vector), and SST (contours; contour interval: $0.02^{\circ} \mathrm{C}$ ) for 10 boreal summers $(1991-2000)$ with respect to the rainfall averaged in the region $\left(5^{\circ} \mathrm{S}-5^{\circ} \mathrm{N}, 80^{\circ}-100^{\circ} \mathrm{E}\right)$ at (a) -5 , (b) -3 , (c) -1 , (d) 0 , (e) +1 , (f) +2 , (g) +3 , and (h) +5 pentads. The rainfall, surface winds, and SST are, respectively, from CMAP, ECMWF analysis, and Reynolds. 


\section{Coupled}
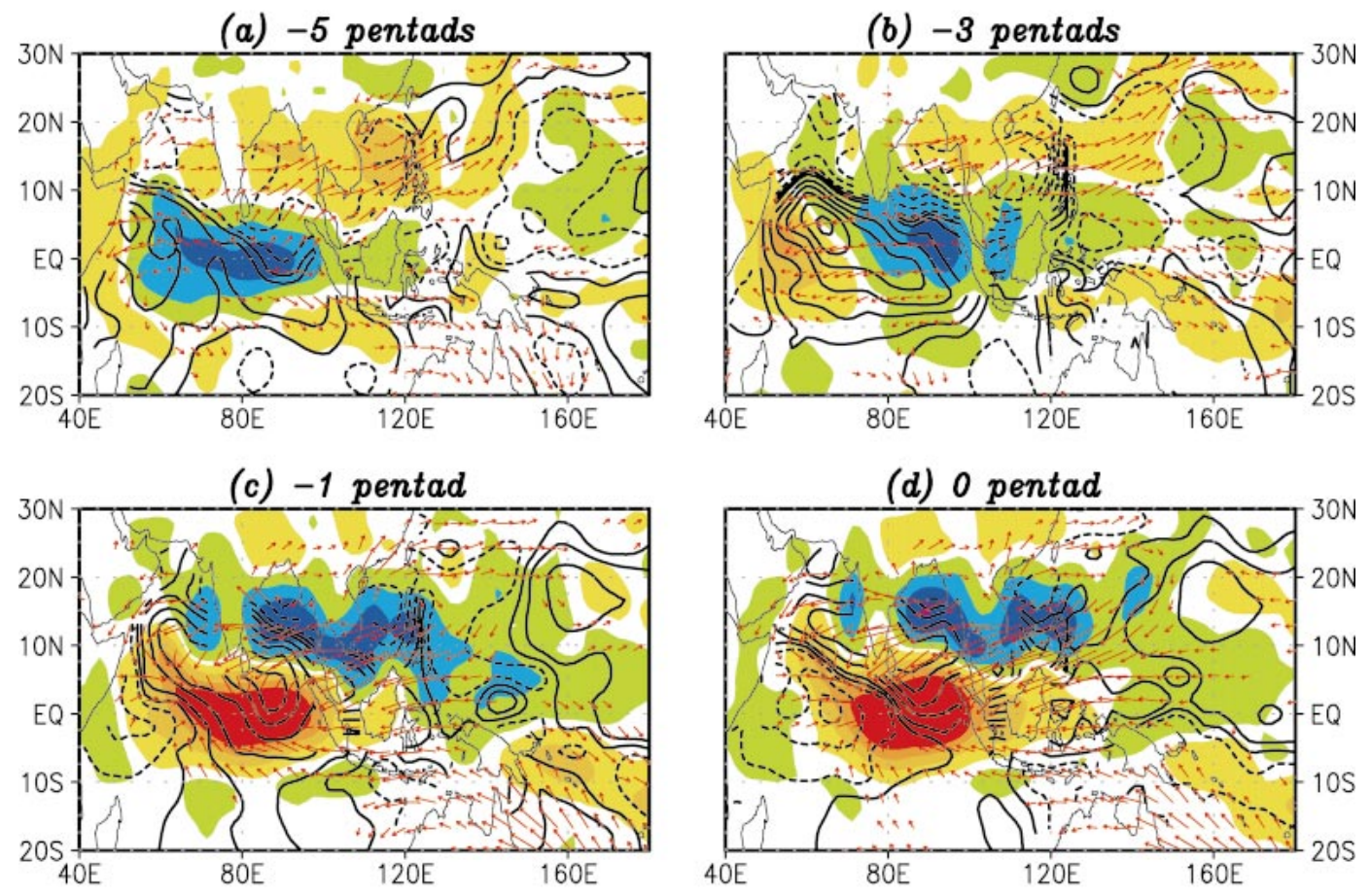

(d) 0 pentad

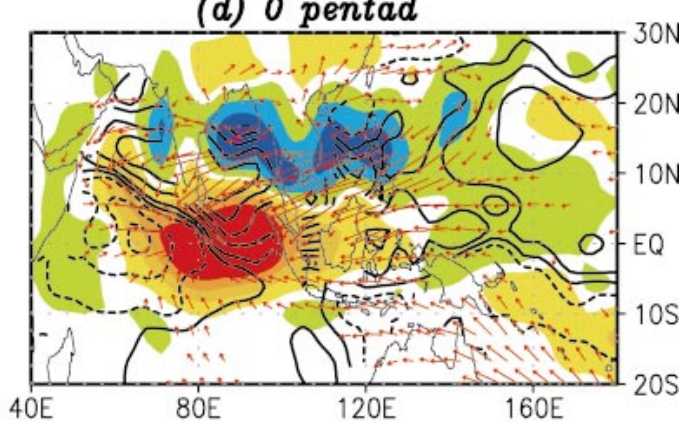

(e) +1 pentad
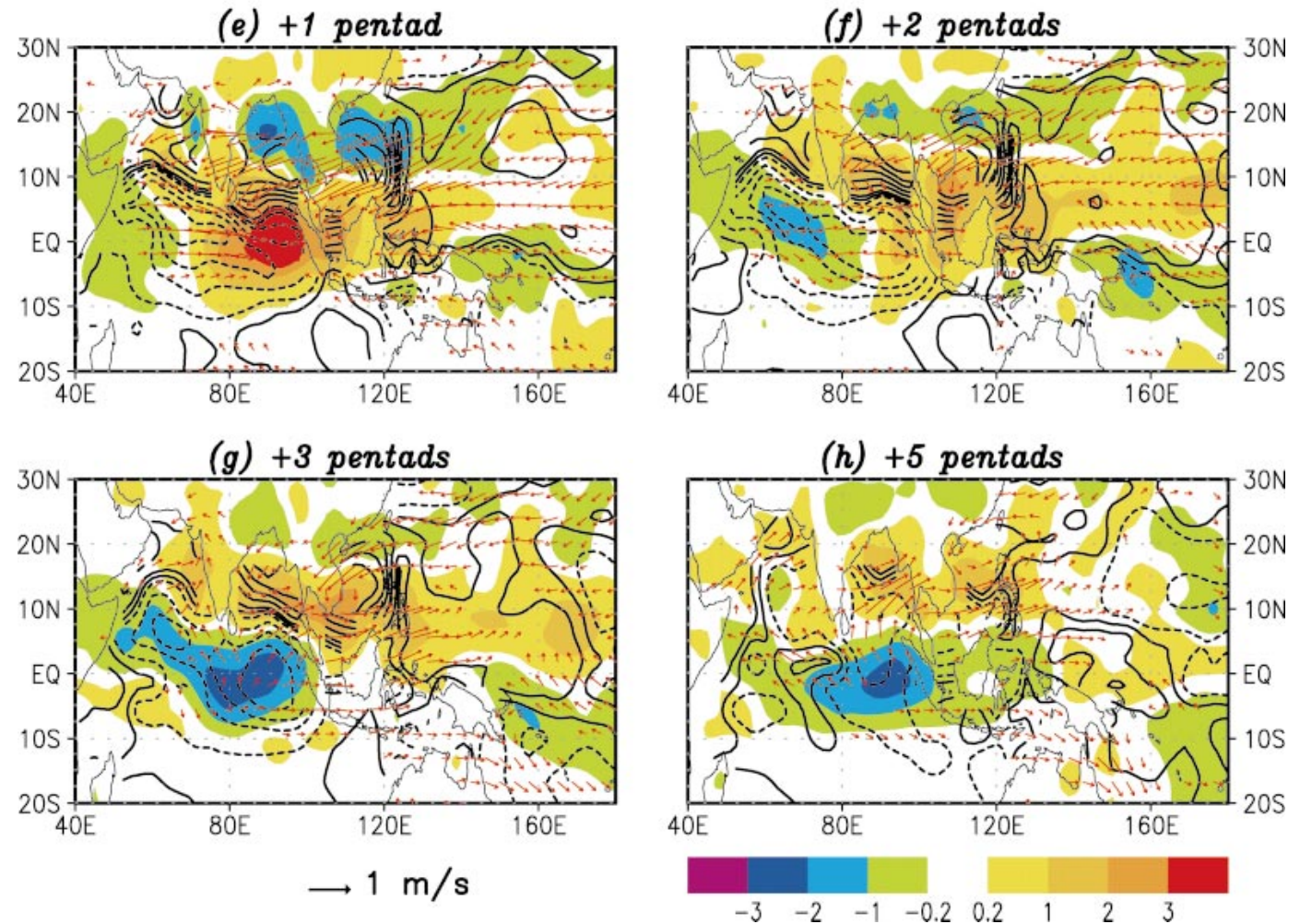

FIG. 4. Same as Fig. 3, but the data are the output from the coupled run. 
the western equatorial Indian Ocean associated with the diminished convection there. Two pentads later (Figs. $3 \mathrm{~b}$ and $4 \mathrm{~b}$ ), the equatorial negative rainfall anomalies move to the eastern Indian Ocean with a negative tongue moving northward into the Arabian Sea, led by underlying negative SST anomalies. The negative SST in the northern Indian Ocean and western Pacific tends to weaken the previous positive rainbelt around $15^{\circ} \mathrm{N}$ and helps it move farther northeastward. The enhanced continent-ocean heat contrast may contribute to the remaining westerly anomalies around $15^{\circ} \mathrm{N}$ at this pentad. The atmospheric cooling associated with the negative rainfall in the central-eastern Indian Ocean forces strong easterly wind anomalies along the equator, which produce moisture convergence in the western Indian Ocean and initiate the onset of another wet cycle (more obvious in the coupled model; Fig. 4b). The increase of downward solar radiation associated with the reduced convection generates a positive anomalous SST patch in the equatorial Indian Ocean. At the same time, a negative SST zone, associated with increased evaporation and reduced solar radiation, prevails in the northern edge of the negative rainfall belt and helps the suppressed convection propagate northeastward.

At -1 pentad (Figs. 3c and 4c), the dry zone stretches from the Arabian Sea to the equatorial western Pacific. The positive rainfall anomaly that was initiated in the Somali coast migrates toward the positive SST area in the equatorial Indian Ocean and is intensified. The Indian subcontinent monsoon shifts to its break phase. Near the equatorial Indian Ocean, the increased rainfall almost collocates with the positive SST in this pentad, but, with the maximum SST located in the northern edge of the maximum rainfall. Different from the observations, a negative SST patch starts to form in the western equatorial Indian Ocean. At 0 pentad (Figs. 3d and 4d), the positive convection is strongest in the eastern Indian Ocean and it starts to generate a negative SST anomaly underneath. A cyclonic Rossby wave response to the equatorial atmospheric heating dominates in the northern Indian Ocean, but the response in the southern Indian Ocean is weak. This meridional asymmetry is attributed to the effects of the strong summer-mean easterly shear on the Rossby wave response in the North Hemisphere (Wang and Xie 1996). The Kelvin wave response strengthens the easterly anomalies over the Maritime Continent and western Pacific. Associated with the enhanced easterly perturbations and reduced rainfall, the sea surface in the north and east of the enhanced convection starts to warm up by reduced latent heat flux and enhanced downward solar radiation. In the western Indian Ocean, surface divergence associated with equatorial westerly perturbations starts to initiate another dry phase (Figs. 3e and 4d). The onset of the dry phase is about one pentad earlier in the model than in the observations. From +1 pentad to +3 pentads (Figs. 3e-g and $4 \mathrm{e}-\mathrm{g}$ ), positive SST anomalies in the northern Indian Ocean and in the western Pacific help the positive rainfall move northeastward. The model SST and rainfall anomalies in the western Pacific are not as well defined as in the observations.

Generally speaking, from -5 pentads to +3 pentads, the coupled model captures the major spatiotemporal evolutions of the observed BSISO in the tropical Asiawestern Pacific region. The dynamically coherent evolutions among CMAP rainfall, ECMWF surface winds, and Reynolds' SST suggest that the BSISO in the Asiawestern Pacific region results from the interactions among the convection, associated atmospheric circulations, and underlying SST. The hybrid coupled model reasonably reproduces this interactive character of the BSISO in terms of the large-scale features.

At +5 pentads, however, the simulation shows considerable discrepancy with the observations. The observed rainfall anomalies have a dominant east-west seesaw pattern with a negative sign in the Indian Ocean and a positive sign in the South China Sea and in the WNP (Fig. 3h). The coupled model, however, shows a north-south dipole with negative rainfall in the equatorial Indian Ocean and positive in the Bay of Bengal and South China Sea (Fig. 4h). One possible reason for this discrepancy of rainfall pattern is the different SST anomalies between the simulation and the observations, particularly over the Bay of Bengal, the South China Sea, and the WNP. In the observations (Fig. 3h), significant negative SST anomalies developed in the above areas. This feature is totally missing in the coupled model. This inadequate simulation of SST cooling is likely due to the lack of salinity effects in the ocean model. As suggested by Lukas and Lindstrom (1991), a saltstratified barrier layer (which is much shallower than the mixed layer defined by vertical thermal profile) forms because of large precipitation in the wet phase of ISO. This would allow the sea surface to cool much faster because of the negative surface heat flux in the wet phase. We will come back to this point later.

\section{2) StAnd-ALONE ATMOSPHERIC MODEL}

The evolutions of the BSISO in the mean run are shown in Fig. 5. At -5 pentads (Fig. 5a), a negative rainfall anomaly appears in the equatorial Indian Ocean and Maritime Continent. In contrast to the observations (Fig. 3a) and the coupled solution (Fig. 4a), no apparent north-south dipole develops in the Indian sector. The positive rainfall anomaly is strongest over the Philippine Islands and the South China Sea. Two pentads later (Fig. $5 b)$, the negative rainfall anomaly in the equatorial Indian Ocean moves to the eastern Indian Ocean. An anomalous rainfall dipole develops on the equatorial Indian Ocean with easterly anomalies crossing the basin. At -1 pentad (Fig. 5c), the positive rainfall anomaly expands eastward to cover the equatorial Indian Ocean and Maritime Continent. A negative rainbelt forms near $15^{\circ} \mathrm{N}$. The rainfall anomalies in both the Bay of Bengal and equatorial region are weaker than their counterparts 


\section{Forced by Monthly-mean SST}
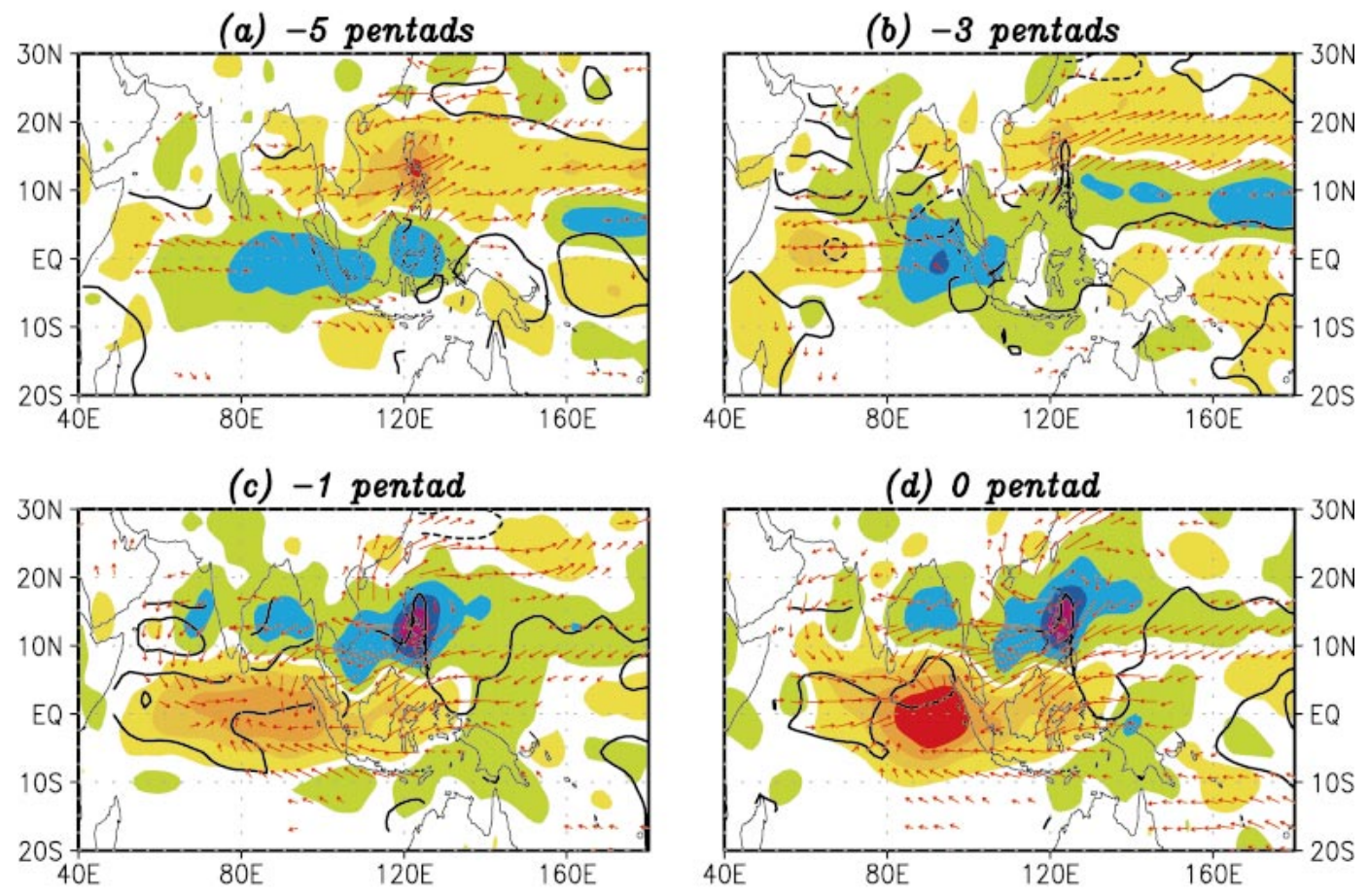

(d) 0 pentad

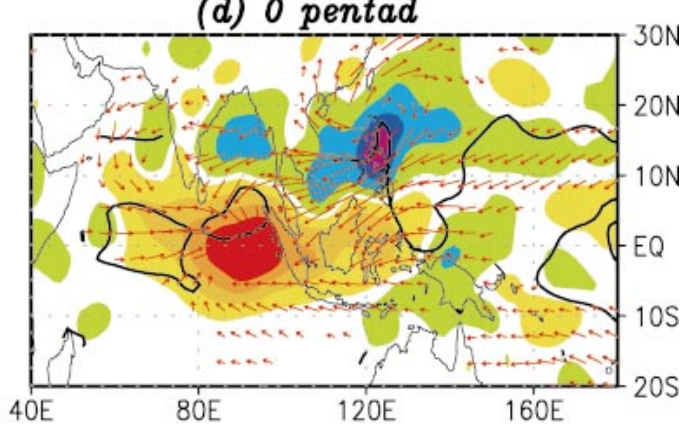

(e) +1 pentad

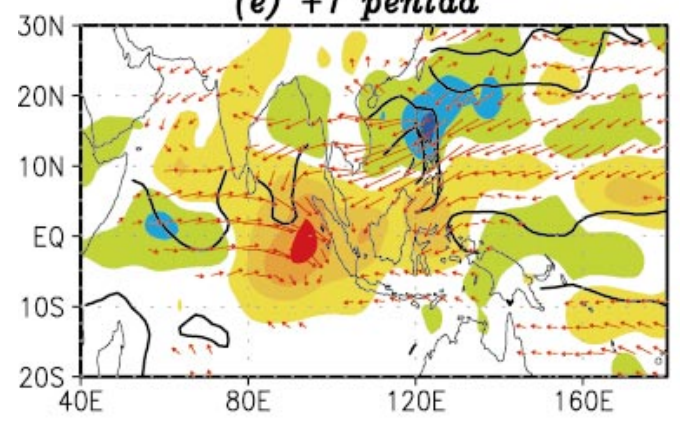

(f) +2 pentads

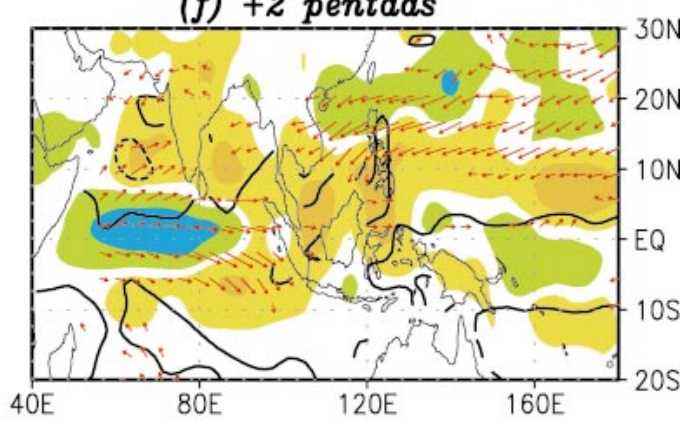

(g) +3 pentads
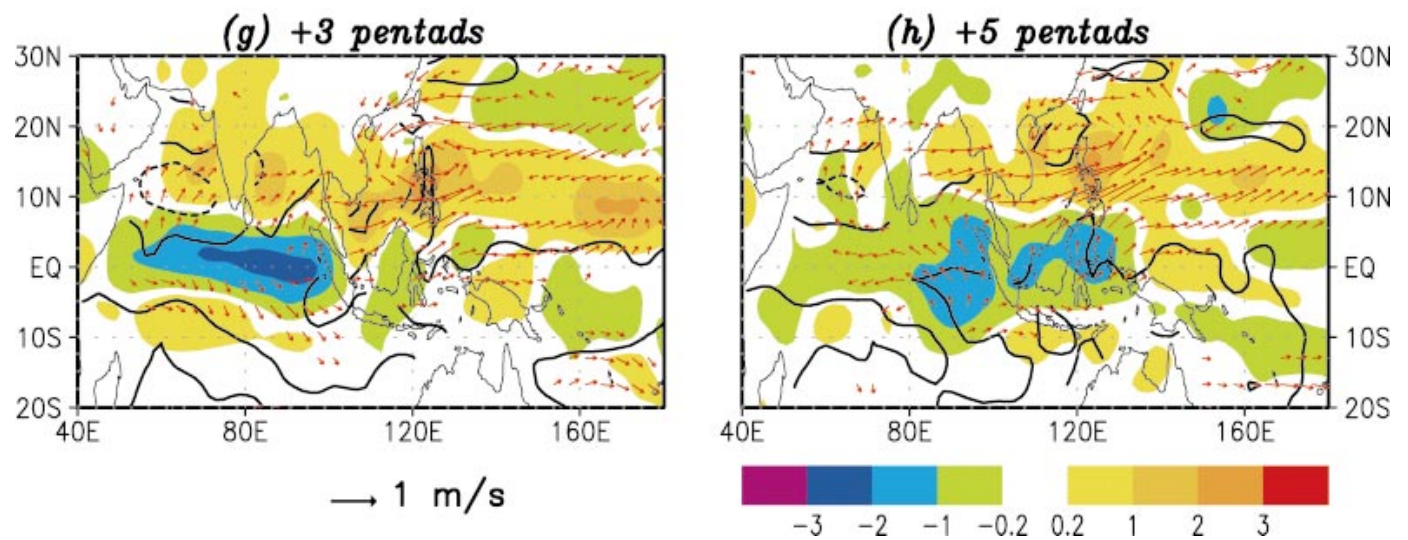

FIG. 5. Same as Fig. 3, but the data are the output from the atmosphere-only run forced with monthly mean SST of the coupled run (the mean run). 
in the coupled run (Fig. 4c). At 0 pentad (Fig. 5d), the maximum rainfall anomaly shifts to the eastern Indian Ocean. Westerly wind anomalies dominate over the equatorial Indian Ocean. A wet tongue extends into the south of the Arabian Sea, signifying the northward propagation in the western Indian Ocean. The strongest negative rainfall anomaly locks on the Philippine Islands. From +1 pentad to +2 pentads (Figs. 5e and 5f), the positive equatorial rainfall moves both northward in the Indian sector and eastward into the western Pacific. Negative rainfall starts to move into the equatorial Indian Ocean again. At +3 pentads (Fig. $5 \mathrm{~g}$ ), a tilted positive rainfall belt forms over the Arabian Sea, Bay of Bengal, South China Sea, and the WNP. The Indian Ocean is dominated by a north-south rainfall dipole. At +5 pentads (Fig. 5h), major positive rainfall stays around the Philippine Islands; the simulation in the western Pacific seems better than that in the coupled run. The negative rainfall along the equator shifts to the eastern Indian Ocean and Maritime Continent. Generally speaking, the gross spatiotemporal evolutions of the BSISO in this atmosphere-only run are similar to those in the coupled run and the observations except with weaker amplitudes and less coherent spatial patterns.

This result suggests that the major characteristics of the BSISO are very likely determined by atmospheric internal dynamics (Wang and Xie 1997). The interactions between the BSISO and underlying ocean primarily increase the intensity of the BSISO and maintain a more coherent spatiotemporal evolution. The stronger intensity in the coupled run implies that the SST fluctuations associated with the BSISO do feed back to the convection positively (Fu et al. 2003). We have compared the SST anomaly pattern and surface wind differences between the coupled run and the mean run from -5 to +5 pentads. At -1 pentad and +3 pentads, the SST gradient seems to significantly contribute to the surface wind differences. At -1 pentad (Fig. 6a), a positive SST patch situates in the central Indian Ocean, with a negative SST over the Bay of Bengal and South China Sea. A cyclonic (anticyclonic) circulation is collocated with a warm (cold) SST patch with air flowing from the cold region to the warm region. A similar scenario appears at +3 pentads (Fig. 6b). A negative SST anomaly region tilts northwest and southeast in the central Indian Ocean and a positive SST anomaly exists over the Bay of Bengal and the South China Sea. A cyclonic (anticyclonic) circulation is over the positive (negative) SST anomaly region. It suggests that the SSTgradient anomalies associated with the BSISO could feed back to the convection through changing the boundary layer winds (Lindzen and Nigam 1987).

\section{The NPISO in the Indian sector}

a. The wavenumber-frequency analysis of the NPISO

As indicated in the previous section, one dominant mode of the BSISO in the Indian sector is the NPISO.

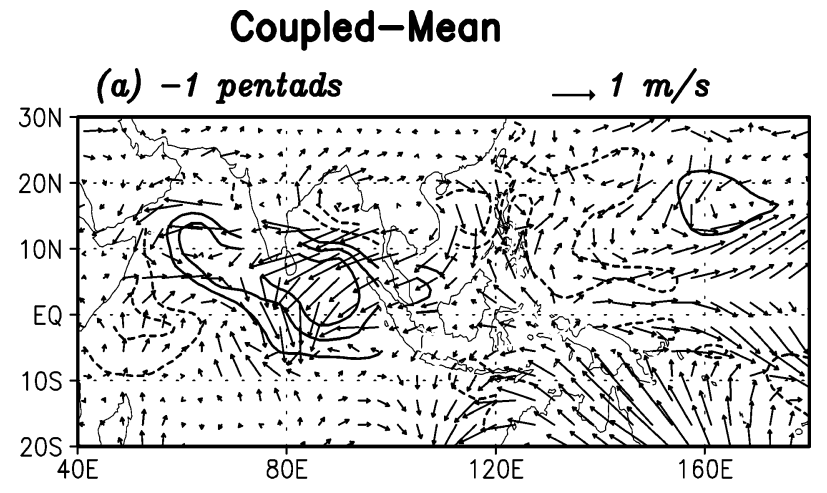

(b) +3 pentads

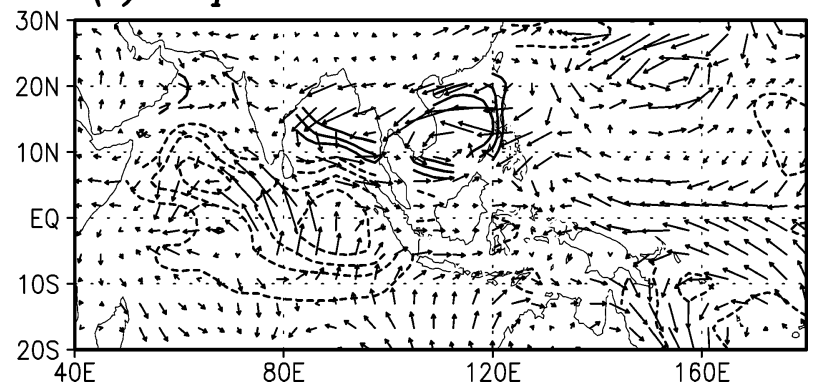

FIG. 6. Differences of surface winds and SSTs (contour interval: $0.02^{\circ} \mathrm{C}$ ) between the coupled run (Fig. 4) and the mean run (Fig. 5) at (a) -1 and (b) +3 pentads.

The disturbances initiated at (or migrated to) the equatorial Indian Ocean tend to propagate northward into the south Asian continent in boreal summer (Yasunari 1979). The better simulation of this intraseasonal mode may improve the predictability of active (break) spells of the south Asian summer monsoon. Following Wheeler and Kiladis (1999) and Teng and Wang (2003), the wavenumber-frequency analysis has been used to summarize the meridional propagating disturbances between $10^{\circ} \mathrm{S}$ and $30^{\circ} \mathrm{N}$ for 10 boreal summers in the Indian sector. Figure 7 presents the 10 -yr mean spectral density averaged in a zonal band extending from $65^{\circ}$ to $95^{\circ} \mathrm{E}$ for the observations (CMAP), the coupled run, and two atmosphere-only runs. In Figs. $7 \mathrm{a}-\mathrm{d}$, the northwardpropagating variances significantly dominate over their southward-propagating counterparts. The periods for the dominant northward-propagating variability are 40-50 days with their wavelengths about $40^{\circ}$ in latitude. The propagating speed is about $1 \mathrm{~m} \mathrm{~s}^{-1}$. The simulated NPISO (particularly in the coupled run and daily run; Figs. $7 \mathrm{~b}$ and $7 \mathrm{c}$ ) is a bit slower (or with a longer period) than that in the CMAP observations. The intensity of the NPISO is strongest in the coupled run (even a bit stronger than the observations) and weakest in the mean run, with the intensity of the daily run in between. The similarity of the three runs does suggest that the atmospheric internal dynamics alone could produce a dominant NPISO in boreal summer over the Indian sector. Including intraseasonal SST forcing or active air-sea coupling ba- 


\section{Phase $\operatorname{speed}(\mathrm{m} / \mathrm{sec})$}
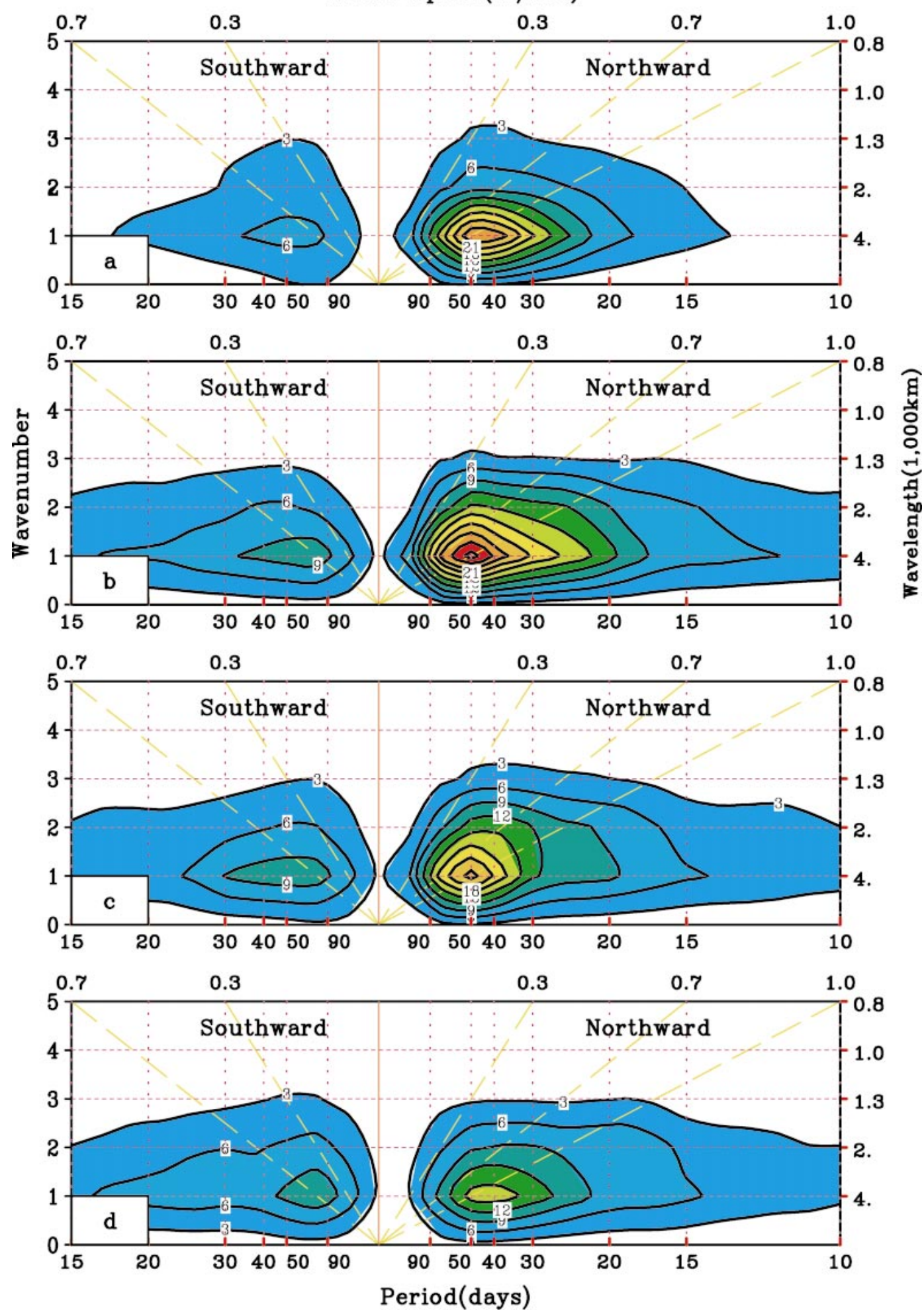

FIG. 7. Wavenumber-frequency spectra of rainfall rate associated with the NPISOs averaged between $65^{\circ}$ and $95^{\circ} \mathrm{E}$ for (a) the observations (CMAP), (b) the coupled run (taken from Fig. 4a in Fu et al. 2003), (c) the atmosphere-only run forced with daily mean SST, and (d) the atmosphere-only run forced with monthly mean SST. The contour interval is $3\left(\mathrm{~mm} \mathrm{day}^{-1}\right)^{2}$. 
sically increases the intensity of the NPISO, probably slowing down the NPISO a little bit, but has no significant impacts on its meridional scale (or wavelength). If just comparing the intensity of the NPISO in the three runs, one may argue that the daily run is more realistic than the coupled run. In the following subsection, the analyses of the phase relationships will suggest the opposite.

\section{b. Phase relationships of the NPISO}

In section $3 \mathrm{a}$, we documented the coherent evolutions of surface winds, SST, and rainfall associated with the BSISO in the entire Asia-western Pacific region. Here, we focus on the NPISO in the Indian sector and further examine the phase relationships among rainfall, SST, surface divergence, vorticity, net surface heat flux $\left(Q_{\text {net }}\right)$, solar radiation $\left(Q_{\mathrm{sw}}\right)$, and latent heat flux $\left(Q_{\mathrm{lat}}\right)$. Lag correlation is used to document these phase relationships with 10 summers' data. We take surface heat flux as being positive into the ocean. Therefore, a positive $Q_{\text {lat }}$ anomaly represents less evaporation from ocean to atmosphere. All correlation coefficients are averaged between $65^{\circ}$ and $95^{\circ} \mathrm{E}$ to represent the large-scale feature in the Indian sector.

Figures 8 and 9 compare the lag correlations of six pairs of variables for the observations and the coupled solution. The observed surface divergence and vorticity are calculated from the ECMWF surface winds. Figures 8a and 9a show that, in the northern Indian Ocean, positive (negative) SST fluctuations lead (lag) convection by about two pentads. Surface convergence is almost in phase with convection from $20^{\circ} \mathrm{S}$ to $20^{\circ} \mathrm{N}$ (Figs. $8 \mathrm{~b}$ and $9 \mathrm{~b}$ ), indicating the strong coupling between convection and surface convergence. Figures $8 c$ and $9 c$ show that positive surface vorticity leads convection with two pentads to 2 days between the equator and $15^{\circ} \mathrm{N}$. These results suggest that both positive SST and positive vorticity work together to lead the equatorial disturbances to move northward. Regarding the phase relationships between the convection and surface heat fluxes, the major difference between the ECMWF analysis and the coupled run is the latent heat fluxes (Figs. $8 \mathrm{f}$ and $9 \mathrm{f}$ ). The maximum surface evaporation lags convection by 3-4 days in the analysis (Fig. 8f) but is almost in phase with each other in the coupled run (Fig. 9f). Because the minimum solar radiation collocates with the convection in both cases (Figs. 8e and 9e), the resultant minimum net surface heat flux lags the convection in the analysis (Fig. 8d) but is almost in phase in the coupled run (Fig. 9d).

The phase difference of latent heat fluxes between the coupled model and ECMWF analysis may not immediately lead to the conclusion that the modeling latent heat flux is wrong. There are several issues that need to be resolved before we could make a final conclusion. First, the above so-called observations of surface heat fluxes are taken from the ECMWF analysis rather than from in situ observations. Second, the in-phase relationship between convection and the maximum evaporation was observed in JASMINE (Webster et al. 2002), though only one NPISO event was captured. Third, Inness and Slingo (2003) found the same kind of phase difference as we found here when they compared their MJO simulations in the Third Hadley Centre Coupled Ocean-Atmosphere GCM (HadCM3) with those in the ECMWF reanalysis. They showed that, over the Indian Ocean, the maximum evaporation lags convection by 3-4 days in the ECMWF reanalysis but is in phase in the HadCM3. In addition, both kinds of phase relationships in the ECMWF analysis (Fig. 8f) and our coupled model (Fig. 9f) were observed in the western Pacific by the TOGA COARE and Tropical Atmosphere Ocean (TAO) array (Zhang and McPhaden 2000) with respect to the eastward-moving MJO. Apparently, more in situ observations in the Indian Ocean are needed to clarify the above discrepancies.

For the two atmosphere-only runs, the lag correlations among rainfall, surface circulations, and heat fluxes are almost the same as those in the coupled run. To save space, no figures are repeated here. However, as we found in the Arabian Sea and Bay of Bengal (Fu et al. 2003), the phase relationship between the rainfall and SST over the Indian Ocean in the daily run (Fig. 10) is quite different from those in the coupled run and the observations. Instead of a quadrature phase relationship (Figs. 8a and 9a), the intraseasonal SST in this forced atmospheric run (Fig. 10) is almost in phase with the convection near the equator and shows a slight lead of the convection by about 2-3 days in the northern Indian Ocean with a maximum correlation coefficient about 0.3 (only half of that in the coupled run). This result indicates that the air-sea coupling will not significantly change the phase relationships between the convection and surface circulations and heat fluxes. On the other hand, it further supports the conclusion that the BSISO solution in the coupled run is more realistic than that in the forced atmospheric run. The possible impacts of air-sea coupling on the predictability of the BSISO are discussed in the last section.

\section{c. Vertical structures of the NPISO}

In order to validate the vertical structures of the simulated NPISO, a composite analysis is used to construct the vertical structures from the ECMWF analysis and the coupled solution. To select the composite events, two criteria are applied to the filtered rainfall data averaged between $85^{\circ}$ and $95^{\circ} \mathrm{E}:$ 1) a positive rainfall anomaly continuously moves northward at least from the equator to $10^{\circ} \mathrm{N} ; 2$ ) in the course of the northward progression, the positive rainfall anomaly larger than 5 $\mathrm{mm}$ day $^{-1}$ must extend more than $10^{\circ}$ in latitude. Once a case is selected, its reference pentad (0) is set at the time when the northward-propagating rainfall anomaly reaches its maximum at $10^{\circ} \mathrm{N}$. With the same criteria, 


\section{Lag-Correlation (OBS)}
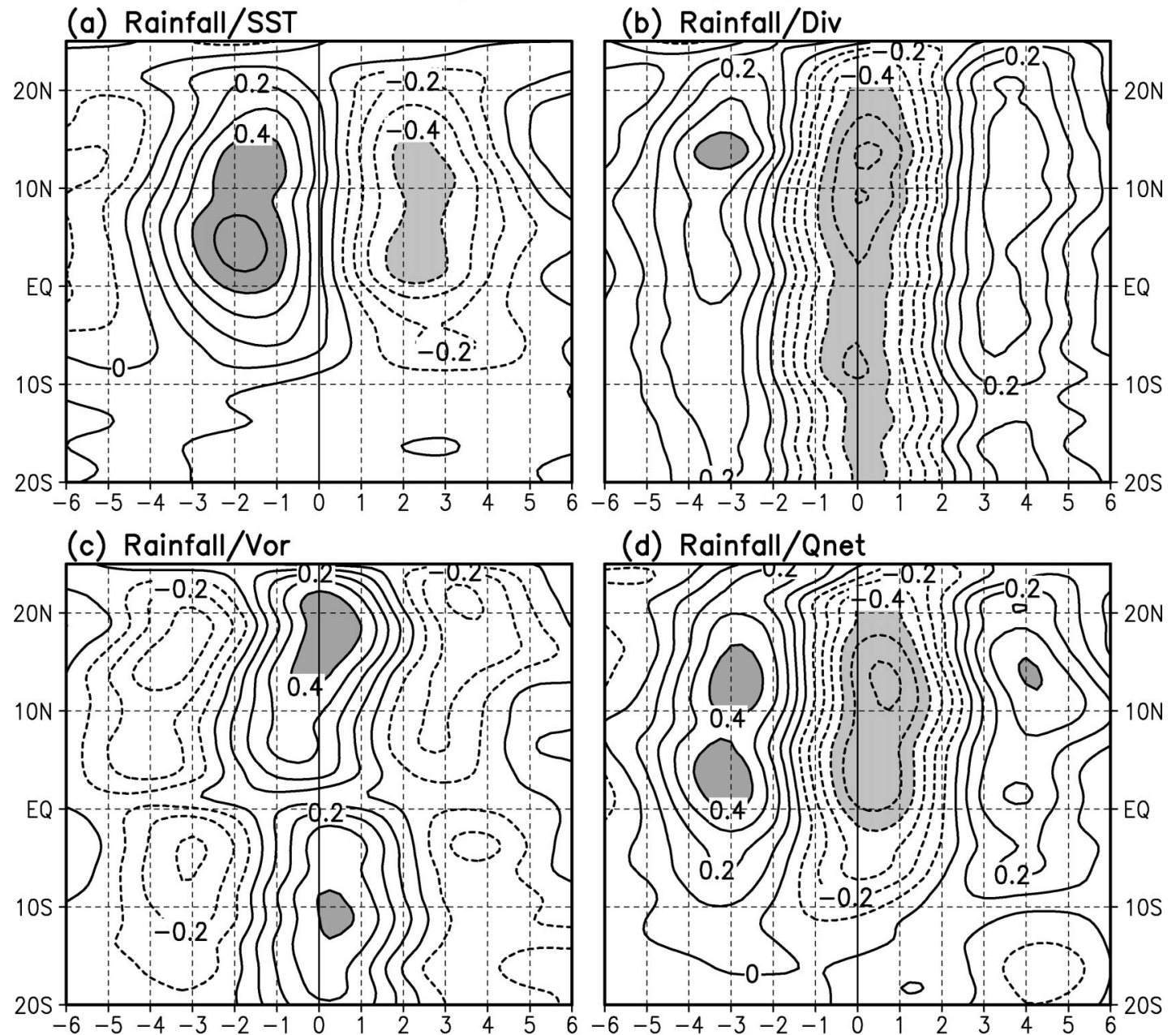

(d) Rainfall/Qnet

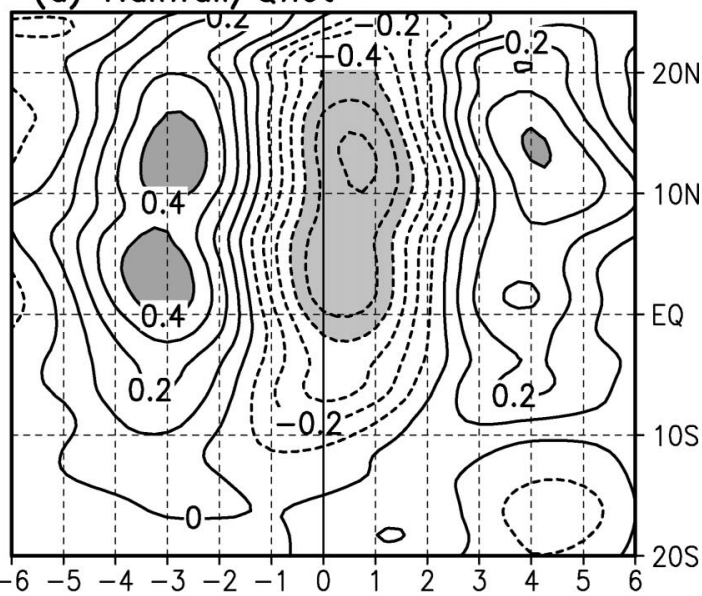

(e) Rainfall/Qsw

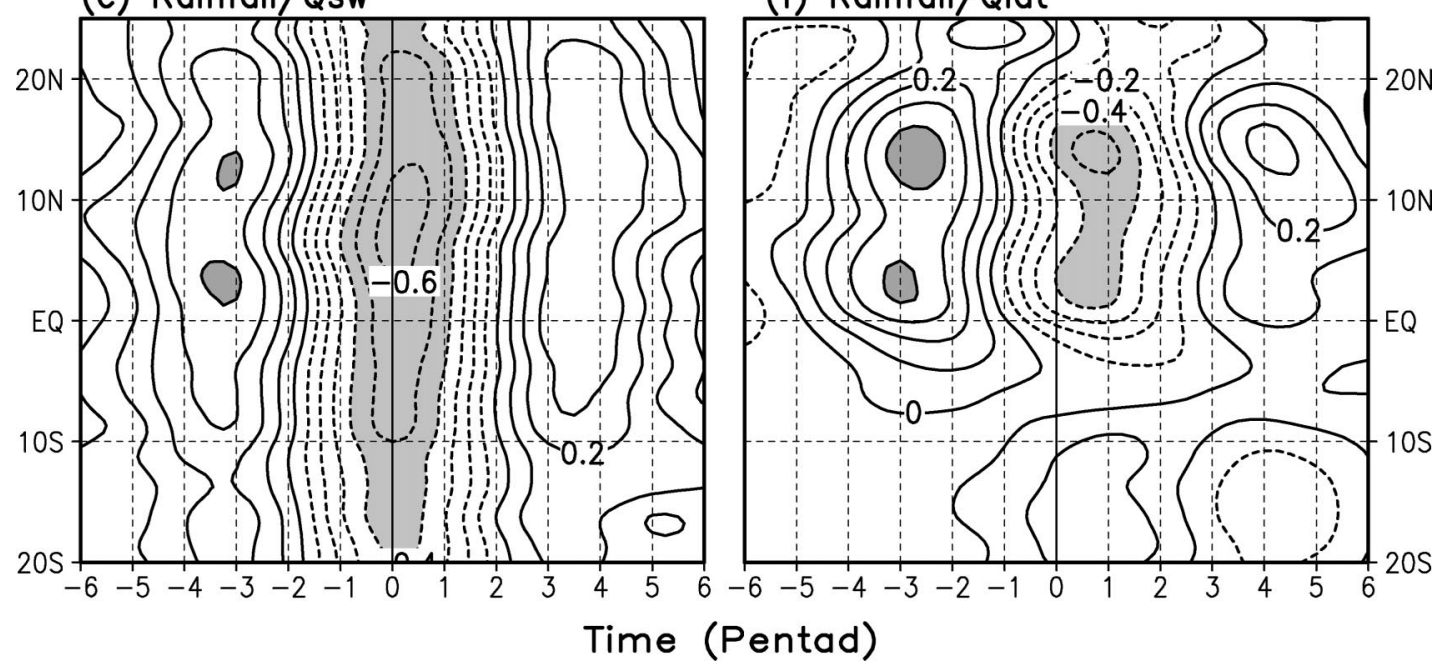

FIG. 8. Lag correlations, averaged over $65^{\circ}$ to $95^{\circ} \mathrm{E}$, between rainfall and (a) SST, (b) surface divergence, (c) surface vorticity, (d) net surface heat flux, (e) downward solar radiation, and (f) surface latent heat flux for 10 boreal summers (1991-2000). Data are from CMAP, ECMWF analysis, and Reynolds SST. 


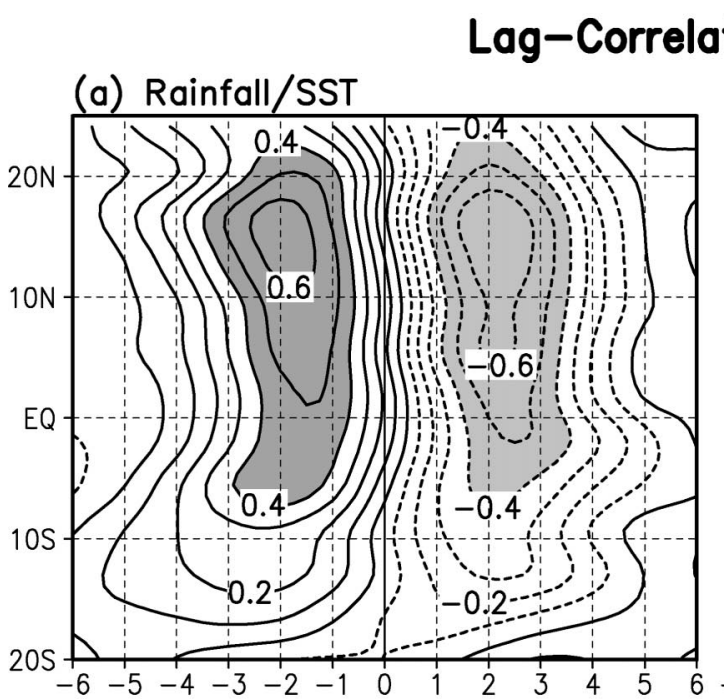

ation (Coupled)
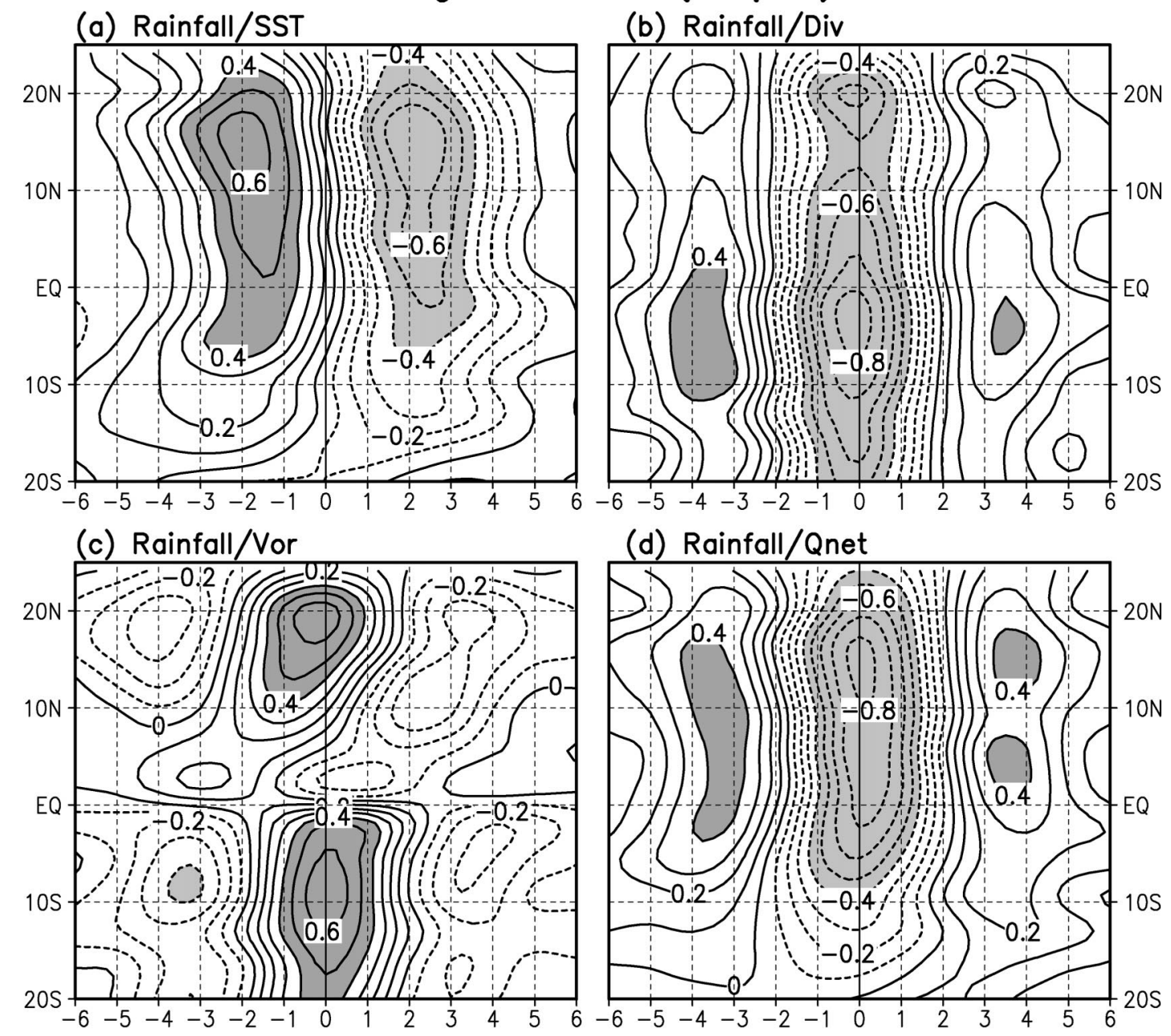

(d) Rainfall/Qnet
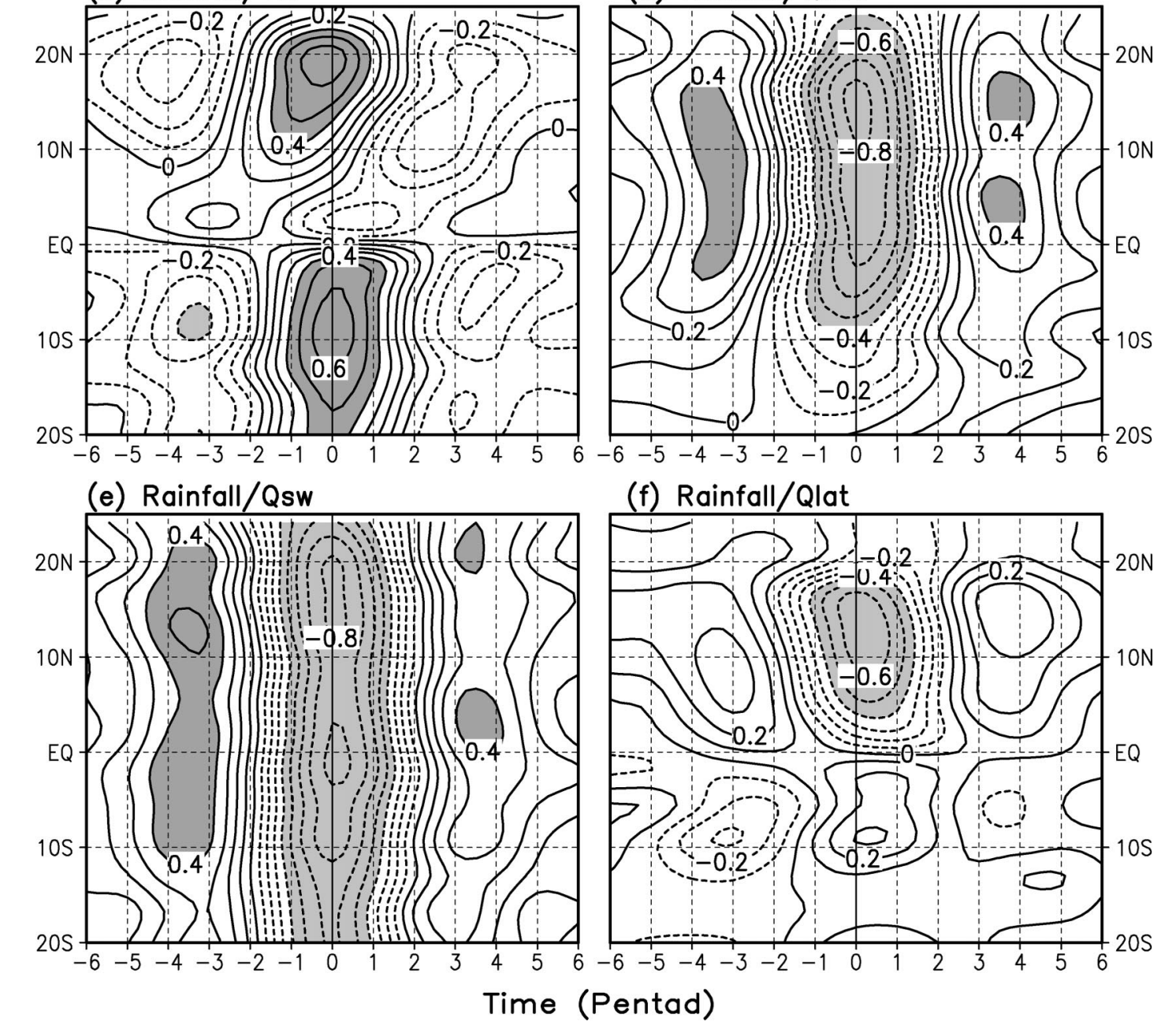

(f) Rainfall/Qlat

FIG. 9. Same as Fig. 8, but the data are the output from the coupled run. 
Lag-Correlation (Daily)

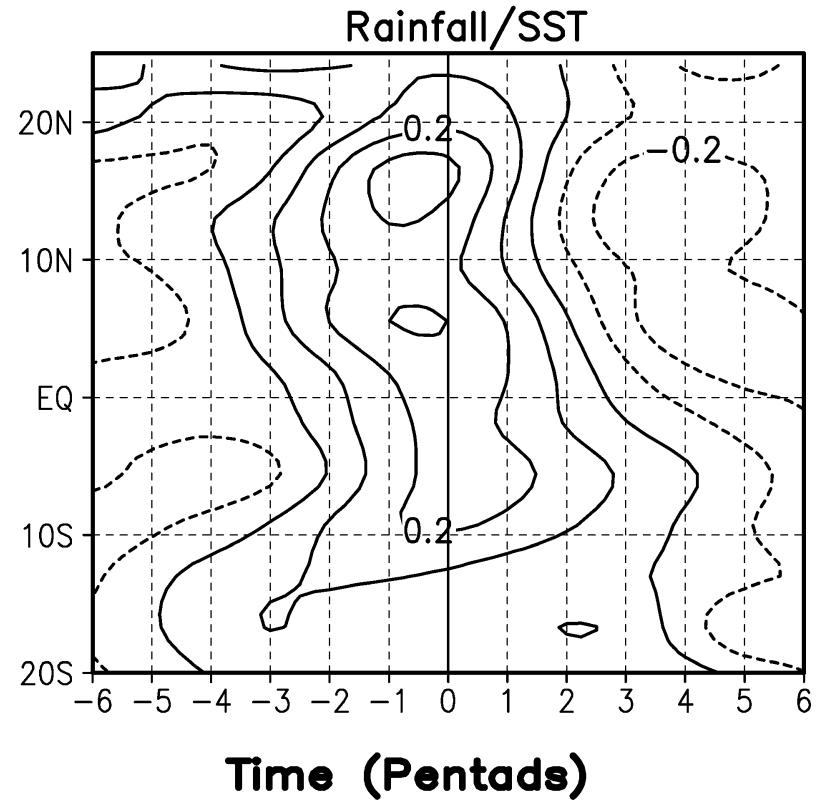

FIG. 10. Lag correlations of rainfall and SST averaged over $65^{\circ}$ and $95^{\circ} \mathrm{E}$ for the atmosphere-only run forced by the daily SST from the coupled run.

15 events are qualified for the observations (CMAP, 1991-2000), 16 events for the coupled solution, 13 events for the atmosphere-only solution forced with daily mean SST, and 5 events for the atmosphere-only solution forced with monthly mean SST. This result indicates that the coupled run produces many more strong northward-propagating events than the mean atmospheric run.

Figure 11 shows the rainfall and SST anomalies associated with the composite NPISO for the observations, the coupled run, and the mean run. No significant SST anomaly appears in the mean run (Fig. 11c) because of the use of monthly mean SST as boundary forcing. The composite rainfall anomalies in both the mean run (5 cases) and the coupled run (15 cases) show coherent northward propagation as in the observations. In both the observations and the coupled run (Figs. 11a and 11b), the composite positive SST anomalies lead the wet phase by a quarter of an ISO cycle with a magnitude about $0.25^{\circ} \mathrm{C}$ near the south Bay of Bengal (about $14^{\circ} \mathrm{N}$ ). In the daily run (figure not shown), the composite rainfall is similar to those in the mean run and the coupled run, while the amplitude of the composite SST anomaly is smaller than that in the coupled run with the SST leading the convection by about 3 days (Fig. 10). In the coupled run, the dry phase that follows the wet phase is relatively weak compared to the observations. The simulated negative SST anomaly is also smaller and lags the observations in the northern Indian Ocean (from $8^{\circ}$ to $15^{\circ} \mathrm{N}$ ), suggesting the oceanic cooling associated with active ISO phase is smaller in the model. The possible cause is discussed later.

Figures 12 and 13 compare the composite vertical structures of moisture and circulations associated with the NPISO at $-3,-1,0,+1,+3$ pentads from ECMWF analysis and the coupled solution. At -3 pentads, the strongest convection appears near the equator in both ECMWF analysis and the coupled solution (Figs. 12a and 13a). The convection, associated with ascending motion, moistens the entire troposphere with maximum moisture perturbation around $700 \mathrm{hPa}$; the magnitude of maximum moisture perturbations (both the positive and the negative) in the coupled solution is considerably larger than that in the analysis. In contrast to the analysis, a negative moisture anomaly is found near the surface at the equator in the coupled run, suggesting that excessively strong dry downdrafts penetrate to the surface in the model. Over the northern Indian Ocean, strong descending motion and tropospheric drying are present in both the observations and the simulation, with the latter having a larger meridional scale. A close meridional circulation, with a first-baroclinic-mode structure, connects the wet and dry phases of the NPISO together, implying that positive feedback may exist between the wet and dry zones through a local Hadley circulation (Lau and Peng 1990). Two pentads later (-1 pentad), the strongest convection moves northward with the ascending branch around $5^{\circ} \mathrm{N}$ (Figs. 12b and 13b). The associated descending branch and drying region also moves northward. Dissimilar to the analysis, the model produces a negative moisture anomaly near the surface in the rainy region and a dry zone in the lower troposphere just south of the equator. The temperature anomalies (Figs. 14a and 14b) at this time show two vertical nodes in the rainy region: positive anomalies below $850 \mathrm{hPa}$ and between 600 and $200 \mathrm{hPa}$; negative anomalies above $200 \mathrm{hPa}$ and between 850 and $600 \mathrm{hPa}$. In the drying region over the northern Indian Ocean, one node dominates with positive anomalies below 500 $\mathrm{hPa}$ and negative anomalies above. The vertical structure and the magnitude of the air temperature anomalies are very similar between the ECMWF analysis and the coupled solution. Ahead of the convection, the combination of boundary layer positive air temperature anomaly and the drying in the troposphere destabilizes the atmosphere and favors the northward movement of the convection. The positive SST anomalies in the northern Indian Ocean warm the boundary layer through vertical mixing, thus contributing to the northward propagation. This boundary layer warming process ahead of the convection is not seen in the atmosphere-only run forced by monthly mean SST (Fig. 14c).

At 0 pentad (Figs. 12c and 13c), the convection moves to $10^{\circ} \mathrm{N}$ in the coupled solution, slightly north of $10^{\circ} \mathrm{N}$ in the ECMWF analysis. Two dry zones appear in the north and south sides of the rainy region. The ascending air associated with convection starts to descend in both north and south sides. Two meridional cells form. At 


\section{Composite Rainfall/SST}

(a) OBS

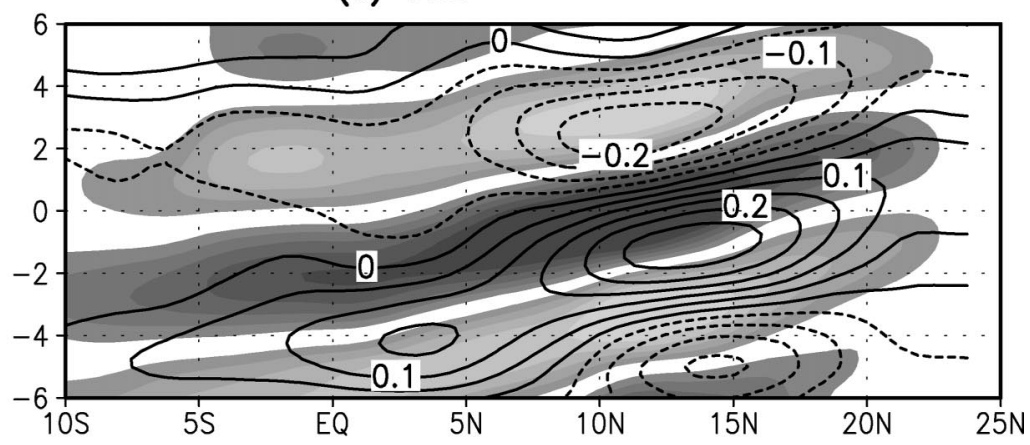

(b) Coupled

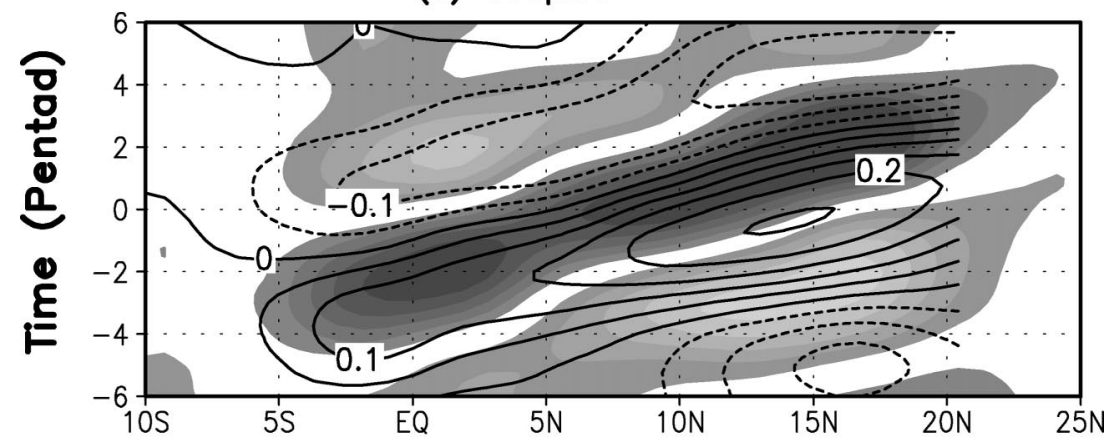

(c) Mean

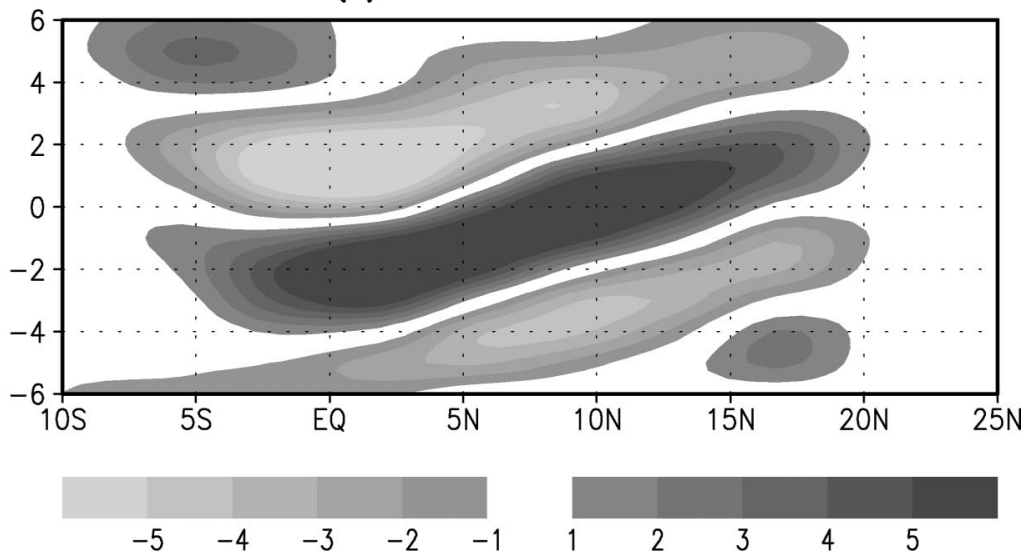

FIG. 11. Composite rainfall (mm day ${ }^{-1}$; shaded) and SST (contours; contour interval: $0.05^{\circ} \mathrm{C}$ ) associated with the NPISOs averaged between $85^{\circ}$ and $95^{\circ} \mathrm{E}$ in (a) the observations ( 15 events), (b) the coupled run (16 events), and (c) the mean run (5 events).

+1 pentad (Figs. 12d and 13d), the south meridional cell starts to intensify and the north one is weakening. The wet phase occupies almost the entire northern Indian Ocean. At +3 pentads, the equatorial dry zone associated with descending motion quickly moves into the northern Indian Ocean in the ECMWF analysis (Fig. $12 \mathrm{e}$ ); the wet zone moves to the north of $15^{\circ} \mathrm{N}$. The coupled solution also indicates the northward intrusion of the dry zone (Fig. 13e); however, the wet phase does not decay as quickly and moves as north as that in the analysis. From -3 pentads to +3 pentads (Figs. 12 and 13), the northward progression of the moisture maximum associated with the NPISO is slower in the coupled model (from $2^{\circ} \mathrm{S}$ to $17^{\circ} \mathrm{N}$ ) than that in the analysis (from $3^{\circ} \mathrm{S}$ to $22^{\circ} \mathrm{N}$ ).

One possible reason for the slow northward movement of the wet phase in the coupled model is the inadequate simulation of sea surface cooling associated with the strong convection in the Bay of Bengal (Figs. $4 \mathrm{~h}$ and $11 \mathrm{~b}$ ). The composite SST cooling in the Bay of 
Bengal $\left(14^{\circ} \mathrm{N}, 90^{\circ} \mathrm{E}\right)$ occurs much faster in the observations than in the coupled run (Fig. 15b). From -1 pentad to +3 pentads, the accumulated negative surface heat flux in the analysis is obviously smaller than that in the coupled model (Fig. 15a). However, the SST drops about $0.55^{\circ} \mathrm{C}$ in the analysis and only $0.34^{\circ} \mathrm{C}$ in the model. In the entire composite cycle, the change of net surface heat flux in the coupled model is actually larger than that in the analysis, while the SST response in the coupled model is smaller, indicating the mixed layer in the model is too deep. If we increase the modeled SST variation by a coefficient of 1.4 (equivalent to a reduction of the mixed-layer depth by about 30\%), SST amplitudes become similar between the coupled model and the observations. ${ }^{1}$ However, the cooling of sea surface in the model is still too slow compared to the analysis. This suggests that the weak cooling rate is not only due to the systematic error in the mixed-layer depth in the coupled model, but particularly in the cooling period. One possible cause of the weak cooling is the lack of salinity effects in the ocean model. The data from JASMINE suggest that a shallow barrier layer forms in the convective phase (Webster et al. 2002). The depth of the barrier layer is about 10-20 m shallower than the thermal mixed layer. The shallow barrier layer increases the efficiency of the negative surface heat flux on cooling the sea surface (Lukas and Lindstrom 1991). Therefore, better representations of salinity effects in the ocean model are needed to improve the simulation of the BSISO.

For the atmosphere-only runs, the composite vertical structures of moisture and circulations at $-3,-1,0$, $+1,+3$ pentads associated with the NPISO are similar to those from the coupled run (figure not shown). The common discrepancies with the ECMWF analysis for both the atmospheric runs and the coupled run are 1) tropospheric moisture fluctuations associated with the NPISO are too large and 2) negative surface moisture perturbations occur in the convective phase of the NPISO.

\section{Summary and discussion}

We have validated the boreal-summer intraseasonal oscillation (BSISO) simulated by a hybrid-coupled model with the ECMWF analysis, CMAP rainfall, and Reynolds' SST. The model captures the large-scale features (e.g., circulations and rainfall) of the Asia-western Pacific summer monsoon (Fig. 1) and the major variability centers of the BSISO (Fig. 2) but also has some systematic errors (e.g., too strong rainfall over the Philippine Islands and too weak rainfall in the WNP). The

\footnotetext{
${ }^{1}$ Considering that the magnitude of SST fluctuations in the Reynolds' dataset is smaller than that in the TMI data and buoy data over the Bay of Bengal (Vecchi and Harrison 2002; Sengupta et al. 2001), more studies are needed to improve our understanding and representation of the processes governing the SST variations in this area.
}

\section{Composite Vertical Structure (ECMWF Analysis)}

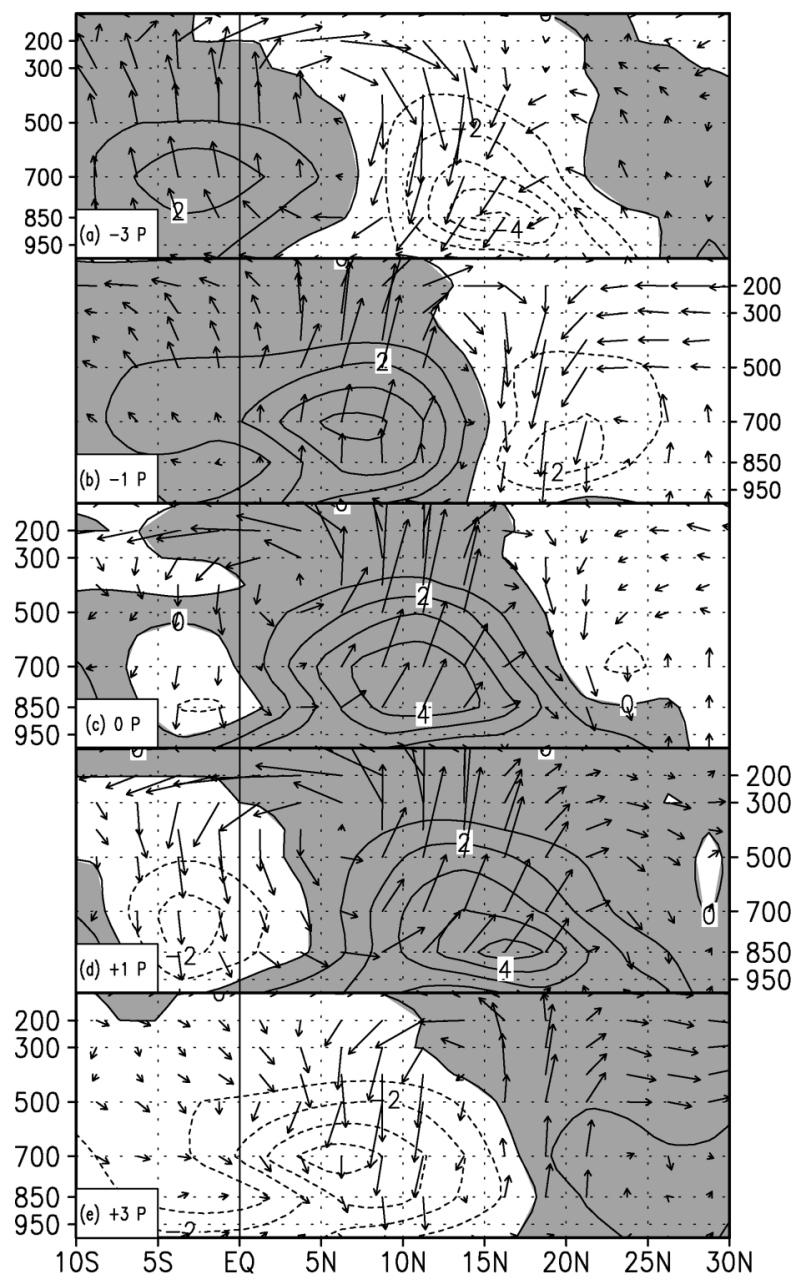

FIG. 12. Composite vertical structures of moisture (contour interval: $0.1 \mathrm{~g} \mathrm{~kg}^{-1}$; positive contours shaded) and circulation perturbations associated with the NPISO in the observations at (a) -3 , (b) -1 , (c) 0 , (d) +1 , and (e) +3 pentads.

observational data (or model analysis) were used to reveal the coherent spatiotemporal evolutions among the convection, atmospheric circulations, and underlying SST of the BSISO (Fig. 3). The coupled model reproduces the observed spatiotemporal evolutions in most of the phases (Fig. 4). Focusing on the Indian sector, the coupled model is able to produce a NPISO with its intensity and dominant period (or propagating speed) all resembling closely those derived from CMAP rainfall (Fig. 7). The lag correlations between the NPISO rainfall and underlying SST, surface convergence, vorticity, and surface heat fluxes suggest that both positive SST and vorticity perturbations act to lead the equatorial disturbances to move northward (Figs. 8 and 9).

A few obvious discrepancies between the coupled solution and the observations are also noticed. First, the ocean component of this coupled model produces very 


\section{Composite Vertical Structure (Coupled)}

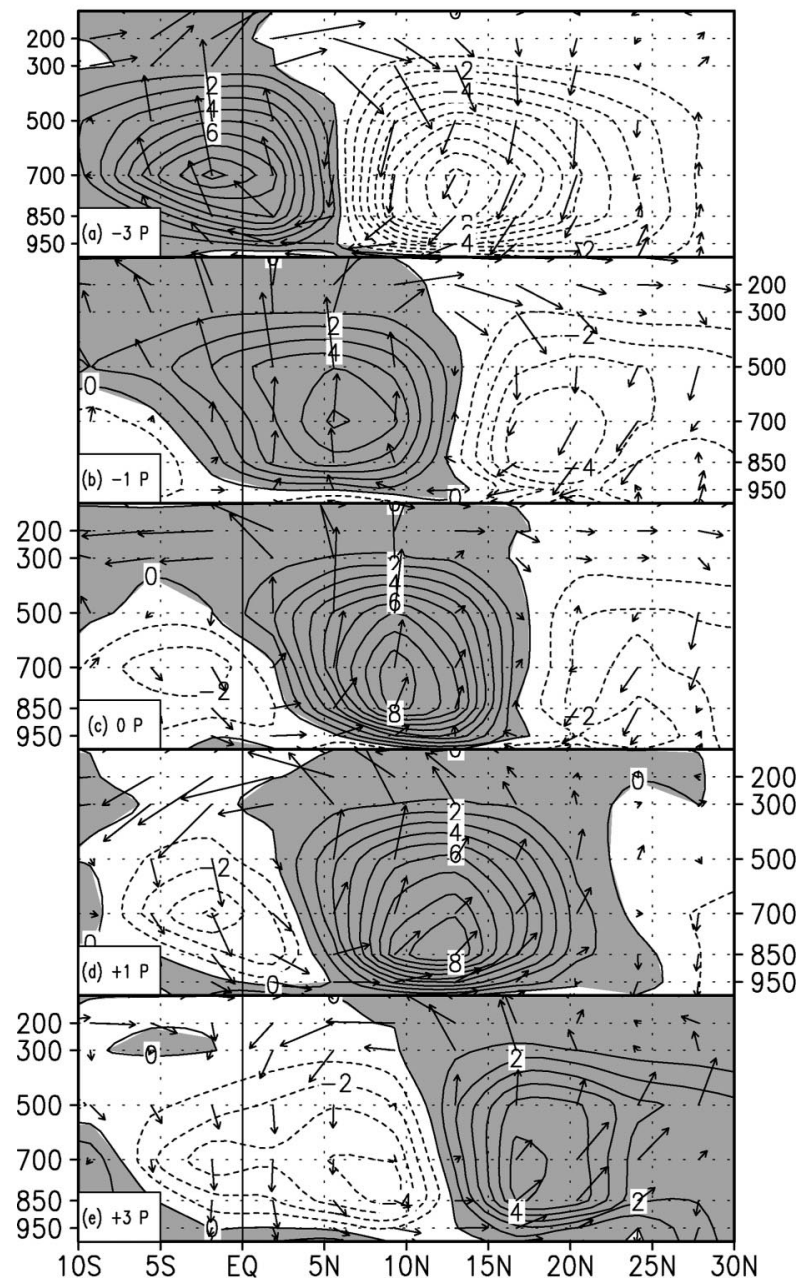

FIG. 13. Same as Fig. 12, but the data are the output from the coupled run.

slow mixed-layer cooling during the active phase of the BSISO, particularly in the Bay of Bengal and South China Sea (Figs. 4h and 15b). We speculate that the lack of salinity effects in the ocean model is the primary cause. The precipitation associated with the active phase of the ISO develops a shallow barrier layer, which could considerably increase the efficiency of mixed-layer cooling (Lukas and Lindstrom 1991). This process is missing in our current ocean model. Second, the phase relationship between latent heat flux and rainfall is slightly different in the coupled solution (Fig. 9f) and in the ECMWF analysis (Fig. 8f). As we discussed in section $4 \mathrm{~b}$, more accurate surface latent heat flux observations are needed to pin down the causes of this discrepancy. Third, the tropospheric moisture fluctuations associated with the NPISO in the coupled solution (also the atmosphere-only solutions) are too large compared to those from the ECMWF analysis (Figs. 12 and

\section{Composite Air Temperature at -1 Pentad}

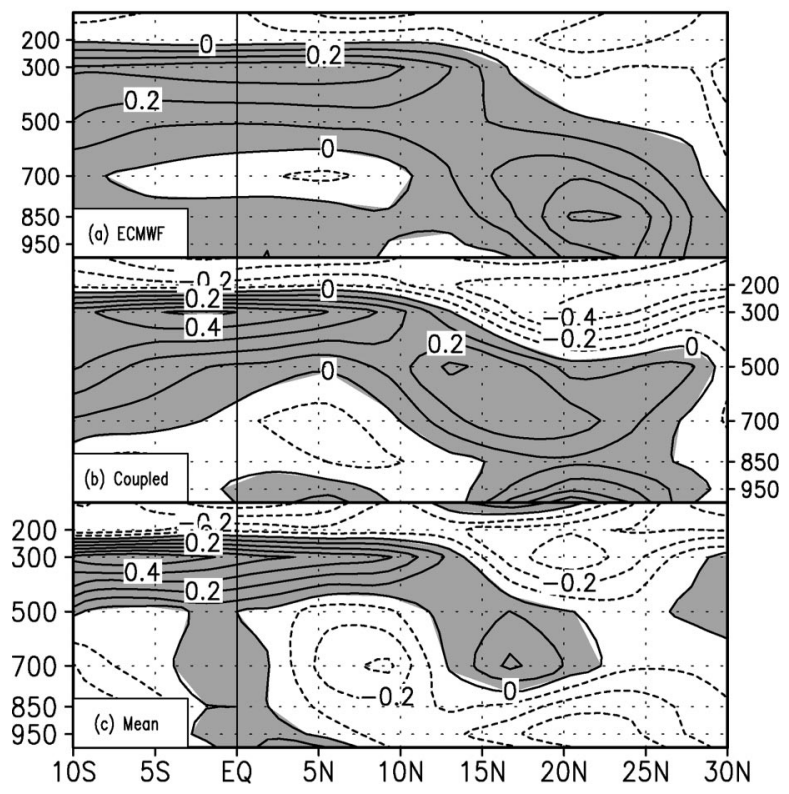

FIG. 14. Composite vertical structures of air temperature perturbations (contour interval: $0.1^{\circ} \mathrm{C}$; positive contours shaded) at -1 pentad for (a) the ECMWF analysis, (b) the coupled run, and (c) the mean run.

13). The near-surface negative moisture perturbations in the convective phase of the BSISO (Figs. 13a and $13 \mathrm{~b})$ suggest that the downdrafts in the ECHAM4 GCM are overestimated.

The intercomparison between the coupled run and two atmospheric runs (the mean and daily runs) suggests that the atmosphere-ocean coupled system is the ultimate tool needed to realistically simulate the BSISO. The coupled run produces the most coherent spatiotemporal evolutions among the convection, the associated circulations, and underlying SST (Figs. 4 and 5). It also has the strongest intensity of the NPISO (Fig. 7) and maintains a correct phase relationship between the convection and SST (Figs. 4 and 9a). The composite analysis reveals that the number of strong NPISOs in the coupled run (16 events; 15 events in the observations) is many more than that in the mean run ( 5 events; 13 events in the daily run). The better simulation in the coupled system is largely attributed to the coherent SST fluctuations associated with the BSISO (Figs. 3 and 4). The intraseasonal SST fluctuations feed back to the convection possibly through changing the convective instability (Fig. 14) and SST-gradient forced surface winds (Fig. 6). On the other hand, the similarities among the three runs [e.g., the spatiotemporal evolutions of rainfall and surface winds (Fig. 5); the characteristics and vertical structures of the NPISO (Figs. 7 and 13); the phase relationships between convection and surface heat fluxes (Fig. 9)] do point out the critical role of a GCM's internal dynamics on the reasonable simulation 


\section{Composite ISO at (14N, 90E)}
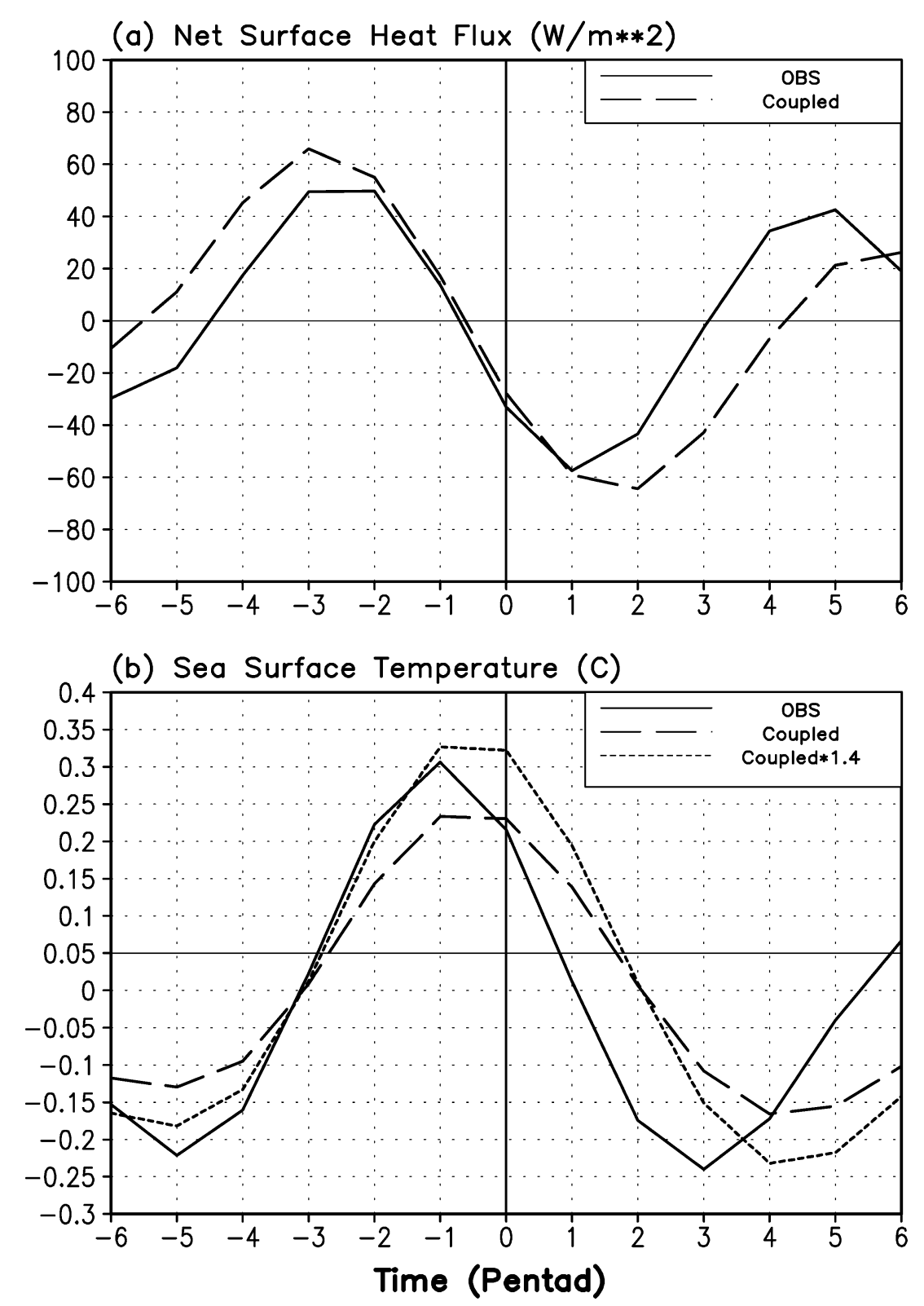

FIG. 15. Composite intraseasonal cycle of (a) net surface heat flux anomalies ( $\mathrm{W} \mathrm{m}^{-2}$ ) and (b) SST anomalies $\left({ }^{\circ} \mathrm{C}\right)$ at the Bay of Bengal $\left(14^{\circ} \mathrm{N}, 90^{\circ} \mathrm{E}\right)$ from the observations and the coupled run.

of the BSISO. In contrast to traditional wisdom about the power of SST as an external boundary forcing in the seasonal and interannual time scales, the atmosphere-only run forced by high-frequency (e.g., daily) SST very likely produces a most unphysical solution of the BSISO compared to the coupled run and the mean run. In the mean run, the simulated BSISO is purely determined by the internal atmospheric dynamics (including active land-atmosphere interaction). In the coupled system, the feedback between the internal atmo- spheric dynamics and underlying sea surface is realistically reflected. For the daily run, most likely, the highfrequency SST interferes with the internal atmospheric dynamics associated with the BSISO in an unrealistic way (Figs. 8a, 9a, and 10).

Finally, the different phase relationship between the convection and SST associated with the BSISO in a coupled system and an atmosphere-only system probably has important implications to the predictability of the BSISO. In the coupled system, the positive SST 
systematically leads the convection by about 10 days (as in the observations). The intraseasonal SST in the coupled system may serve as a memory to extend the predictability of the BSISO, while the intraseasonal SST in the atmosphere-only system very likely acts as a false external boundary forcing (Wu et al. 2002; Waliser et al. 2003c, 16-19; Fu and Wang 2004). If the interaction between the convection and large-scale circulations (purely internal atmospheric dynamics) can give a useful BSISO prediction of about 15 days (Waliser et al. 2003b), the SST signal forced by the convection and large-scale circulations in a coupled system might extend our predictability to about 1 month. This hypothesis is under investigation.

Acknowledgments. The authors appreciate Drs. L. Bengtsson, E. Roeckner, L. Dumenil, and U. Schulzweida at the Max Planck Institute for Meteorology for their kind help in the implementation of ECHAM4 GCM at the IPRC. XF thanks R. Lukas for helpful discussions. This research was supported by the NASA Earth Science Program, NSF Climate Dynamics Program, and by the Japan Agency for Marine-Earth Science and Technology (JAMSTEC) through its sponsorship of the IPRC.

\section{REFERENCES}

Bhat, G. S., and Coauthors, 2001: BOBMEX: The Bay of Bengal Monsoon Experiment. Bull. Amer. Meteor. Soc., 82, 2217-2243.

Blade, I., and D. L. Hartmann, 1993: Tropical intraseasonal oscillations in a simple nonlinear model. J. Atmos. Sci., 50, 29222939.

Chang, C.-P., 1977: Viscous internal gravity waves and low-frequency oscillations in the Tropics. J. Atmos. Sci., 34, 901-910.

Flatau, M., P. Flatau, P. Phoebus, and P. Niller, 1997: The feedback between equatorial convection and local radiative and evaporative processes: The implications for intraseasonal oscillations. J. Atmos. Sci., 54, 2373-2386.

Fu, X., and B. Wang, 2001: A coupled modeling study of the annual cycle of the Pacific cold tongue. Part I: Simulation and sensitivity experiments. J. Climate, 14, 765-779.

— , and —_, 2004: Differences of boreal-summer intraseasonal oscillations simulated in an atmosphere-ocean coupled model and an atmosphere-only model. J. Climate, 17, 1263-1271.

_ - — , and T. Li, 2002: Impacts of air-sea coupling on the simulation of mean Asian summer monsoon in the ECHAM4 model. Mon. Wea. Rev., 130, 2889-2903.

— — — - — , and J. P. McCreary, 2003: Coupling between northward-propagating, intraseasonal oscillations and sea surface temperature in the Indian Ocean. J. Atmos. Sci., 60, 1733-1753.

Gadgil, S., and S. Sajani, 1998: Monsoon precipitation in the AMIP runs. Climate Dyn., 14, 659-689.

Gaspar, P., 1988: Modeling the seasonal cycle of the upper ocean. $J$. Phys. Oceanogr., 18, 161-180.

Grabowski, W. W., 2003: MJO-like coherent structures: Sensitivity simulations using the cloud-resolving convective parameterization. J. Atmos. Sci., 60, 847-864.

Hayashi, Y., 1982: Space-time spectral analysis and its applications to atmospheric waves. J. Meteor. Soc. Japan, 60, 156-171.

Hendon, H. H., 2000: Impact of air-sea coupling on the MaddenJulian oscillation in a general circulation model. J. Atmos. Sci., 57, 3939-3952.

- and M. L. Salby, 1994: The life cycle of the Madden-Julian oscillation in a general circulation model. J. Atmos. Sci., 51, 2225-2237.
Hu, Q., and D. A. Randall, 1994: Low-frequency oscillations in radiative-convective systems. J. Atmos. Sci., 51, 1089-1099.

Inness, P. M., and J. M. Slingo, 2003: Simulation of the MaddenJulian oscillation in a coupled general circulation model. Part I: Comparison with observations and an atmosphere-only GCM. J. Climate, 16, 345-364.

Kang, I.-S., C.-H. Ho, Y.-K. Lim, and K.-M. Lau, 1999: Principal modes of climatological seasonal and intraseasonal variations of the Asian summer monsoon. Mon. Wea. Rev., 127, 322-340.

— , and Coauthors, 2002: Intercomparison of the climatological variations of Asian summer monsoon precipitation simulated by 10 GCMs. Climate Dyn., 19, 383-395.

Kawamura, R., R. T. Murakami, and B. Wang, 1996: Tropical and midlatitude 45-day perturbations during the northern summer. $J$. Meteor. Soc. Japan, 74, 867-890.

Kemball-Cook, S., and B. Wang, 2001: Equatorial waves and air-sea interaction in the boreal summer intraseasonal oscillation. $\mathrm{J}$. Climate, 14, 2923-2942.

- - - and X. Fu, 2002: Simulation of the ISO in the ECHAM4 model: The impact of coupling with an ocean model. J. Atmos. Sci., 59, 1433-1453.

Krishnamurti, T. N., 1985: Summer monsoon experiment-A review. Mon. Wea. Rev., 113, 1590-1626.

— - D. K. Oosterhof, and A. V. Mehta, 1988: Air-sea interaction on the time scale of 30 to 50 days. J. Atmos. Sci., 45, 13041322 .

- M. Subramaniam, G. Daughenbaugh, D. Oosterhof, and J. Xue, 1992: One-month forecasts of wet and dry spells of the monsoon. Mon. Wea. Rev., 120, 1191-1223.

Lau, K. M., and P. H. Chan, 1986: Aspects of the 40-50 day oscillation during the northern summer as inferred from outgoing longwave radiation. Mon. Wea. Rev., 114, 1354-1367.

—_, and L. Peng, 1987: Origin of low frequency (intraseasonal) oscillations in the tropical atmosphere. Part I: The basic theory. J. Atmos. Sci., 44, 950-972.

$\longrightarrow$, and —_, 1990: Origin of low frequency (intraseasonal) oscillations in the tropical atmosphere. Part III: Monsoon dynamics. J. Atmos. Sci., 47, 1443-1462.

— K. M. Kim, and S. Yang, 2000: Dynamical and boundary forcing characteristics of regional components of the Asian summer monsoon. J. Climate, 13, 2461-2482.

Lee, M. I., I.-S. Kang, J.-K. Kim, and B. E. Mapes, 2001: Influences of cloud-radiation interaction on simulating tropical intraseasonal oscillation with an atmospheric general circulation model. J. Geophys. Res., 106, 14 219-14 233.

Lindzen, R. S., and S. Nigam, 1987: On the role of sea surface temperature gradients in forcing low-level winds and convergence in the Tropics. J. Atmos. Sci., 45, 2440-2458.

Lukas, R., and E. Lindstrom, 1991: The mixed layer of the western equatorial Pacific Ocean. J. Geophys. Res., 96, 3343-3357.

Madden, R. A., and P. R. Julian, 1971: Detection of a 40-50 day oscillation in the zonal wind in the tropical Pacific. J. Atmos. Sci., 28, 702-708.

Maloney, E. D., and D. L. Hartmann, 2001: The sensitivity of intraseasonal variability in the NCAR CCM 3 to changes in convective parameterization. J. Climate, 14, 2015-2034.

McCreary, J. P., and Z. J. Yu, 1992: Equatorial dynamics in a 2.5layer model. Progress in Oceanography, Vol. 29, Pergamon, 61132.

Mo, K. C., 2000: Intraseasonal modulation of summer precipitation over North America. Mon. Wea. Rev., 128, 1490-1505.

Myers, D. S., and D. E. Waliser, 2003: Three-dimensional water vapor and cloud variations associated with the Madden-Julian oscillation during Northern Hemisphere winter. J. Climate, 16, 929 950.

Neelin, D. J., and J. Y. Yu, 1994: Modes of tropical variability under convective adjustment and the Madden-Julian oscillation. Part I: Analytical theory. J. Atmos. Sci., 51, 1876-1894.

Nordeng, T. E., 1994: Extended version of the convective parameterization scheme at ECMWF and their impact on the mean and 
transient activity of the model in the Tropics. ECMWF Research Department Tech. Memo. 206, European Centre for MediumRange Weather Forecasts, Reading, United Kingdom, 41 pp.

Rajendran, K., A. Kitoh, and O. Arakawa, 2004: Monsoon low-frequency intraseasonal oscillation and ocean-atmosphere coupling over the Indian Ocean. Geophys. Res. Lett., 31, L02210, doi: 10.1029/2003GL019031.

Raymond, D. J., 2001: A new model of the Madden-Julian oscillation. J. Atmos. Sci., 58, 2807-2819.

Reynolds, R. W., and T. M. Smith, 1994: Improved global sea surface temperature analyses using optimum interpolation. J. Climate 7, 929-948.

Roeckner, E., and Coauthors, 1996: The atmospheric general circulation model ECHAM4: Model description and simulation of present-day climate. Max Planck Institute for Meteorology Rep. $218,90 \mathrm{pp}$.

Rui, H., and B. Wang, 1990: Development characteristics and dynamic structure of tropical intraseasonal convection anomalies. J. Atmos. Sci., 47, 357-379.

Sengupta, D., B. N. Goswami, and R. Senan, 2001: Coherent intraseasonal oscillations of ocean and atmosphere during the Asian summer monsoon. Geophys. Res. Lett., 28, 4127-4130.

Slingo, J. M., and Coauthors, 1996: Intraseasonal oscillations in 15 atmospheric general circulation models: Results from an AMIP diagnostic subproject. Climate Dyn., 12, 325-357.

Sperber, K. R., J. M. Slingo, P. M. Inness, and K. M. Lau, 1997: On the maintenance and initiation of the intraseasonal oscillation in the NCEP/NCAR reanalysis and the GLA and UKMO AMIP simulations. Climate Dyn., 13, 769-795.

Taylor, K. E., D. Williamson, and F. Zwiers, 2000: The sea surface temperature and sea-ice concentration boundary condition for AMIP II simulations. PCMDI Rep. 60, Program for Climate Model Diagnosis and Intercomparison, Lawrence Livermore National Laboratory, Livermore, CA, $25 \mathrm{pp}$. [Available online at http:// www-pcmdi.llnl.gov/amip/AMIP2EXPDSN/BCS/amip2bcs. html.]

Teng, H., and B. Wang, 2003: Interannual variations of the boreal summer intraseasonal oscillation in the Asian-Pacific region. $J$. Climate, 16, 3572-3584.

Tiedtke, M., 1989: A comprehensive mass flux scheme for cumulus parameterization in large-scale models. Mon. Wea. Rev., 117, $1779-1800$.

Tokioka, T., K. Yamazaki, A. Kitoh, and T. Ose, 1988: The equatorial 30-60 day oscillation and the Arakawa-Schubert penetrative cumulus parameterization. J. Meteor. Soc. Japan, 66, 883-901.

Tompkins, A. M., 2001: On the relationship between tropical convection and sea surface temperature. J. Climate, 14, 633-637.

Vecchi, G., and D. E. Harrison, 2002: Monsoon breaks and subseasonal sea surface temperature variability in the Bay of Bengal. J. Climate, 15, 1485-1493.

Waliser, D. E., K. M. Lau, and J. H. Kim, 1999: The influence of coupled sea surface temperatures on the Madden-Julian oscillation: A model perturbation experiment. J. Atmos. Sci., 56, 333358.

_, and Coauthors, 2003a: AGCM simulations of intraseasonal variability associated with the Asian summer monsoon. Climate Dyn., 21, 423-446.

- K. M. Lau, W. Stern, and C. Jones, 2003b: Potential predict- ability of the Madden-Julian oscillation. Bull. Amer. Meteor. Soc., 84, 1191-1196.

— - S. Schubert, A. Kumar, K. Weickmann, and R. Dole, 2003c: Proc. Workshop on Modeling, Simulation and Forecasting of Subseasonal Variability. Vol. 25, NASA/CPC-2003-104606, College Park, MD, NASA.

Wang, B., 1988: Dynamics of tropical low-frequency waves: An analysis of the moist Kelvin wave. J. Atmos. Sci., 45, 2051-2065.

—_ and H. Rui, 1990: Synoptic climatology of transient tropical intraseasonal convection anomalies: 1975-1985. Meteor. Atmos. Phys., 44, 43-61.

_- and X. Xie, 1996: Low-frequency equatorial waves in sheared zonal flow. Part I: Stable waves. J. Atmos. Sci., 53, 449-467.

_ , and — 1997: A model for the boreal summer intraseasonal oscillation. J. Atmos. Sci., 54, 72-86.

__ and _ 1998: Coupled modes of the warm pool climate system. Part I: The role of the air-sea interaction in maintaining the Madden-Julian oscillation. J. Climate, 11, 2116-2135.

— T. Li, and P. Chang, 1995: An intermediate model of the tropical Pacific Ocean. J. Phys. Oceanogr., 25, 1599-1616.

Wang, W., and M. E. Schlesinger, 1999: The dependence on convection parameterization of the tropical intraseasonal oscillation simulated by the UIUC 11-layer atmospheric GCM. J. Climate, 12, 1423-1457.

Webster, P. J., 1983: Mechanisms of monsoon low-frequency variability: Surface hydrological effects. J. Atmos. Sci., 40, 2110 2124.

_, and R. Lukas, 1992: TOGA COARE: The Coupled OceanAtmosphere Response Experiment. Bull. Amer. Meteor. Soc., 73, $1377-1416$.

_, V. O. Magana, T. N. Palmer, J. Shukla, R. A. Tomas, M. Yanai, and T. Yasunari, 1998: Monsoons: Processes, predictability, and the prospects for prediction. J. Geophys. Res., 103C, 14 45114510.

— Meteor. Soc., 83, 1603-1629.

Wheeler, M., and G. N. Kiladis, 1999: Convectively coupled equatorial waves: Analysis of clouds and temperature in the wavenumber-frequency domain. J. Atmos. Sci., 56, 374-399.

Wu, M. L. C., S. Schubert, I. S. Kang, and D. E. Waliser, 2002: Forced and free intraseasonal variability over the south Asian monsoon region simulated by 10 AGCMs. J. Climate, 15, 28622880.

Xie, P., and P. A. Arkin, 1997: Global precipitation: A 17-year monthly analysis based on gauge observations, satellite estimates, and numerical model outputs. Bull. Amer. Meteor. Soc., 78, 25392558.

Yasunari, T., 1979: Cloudiness fluctuations associated with the Northern Hemisphere summer monsoon. J. Meteor. Soc. Japan, 57, 227-242.

Zhang, C., 1996: Atmospheric intraseasonal variability at the surface in the tropical western Pacific ocean. J. Atmos. Sci., 53, 739758.

—_ and M. J. McPhaden, 2000: Intraseasonal surface cooling in the equatorial western Pacific. J. Climate, 13, 2261-2276.

Zheng, Y., D. E. Waliser, W. F. Stern, and C. Jones, 2004: The role of coupled sea surface temperatures in the simulation of the tropical intraseasonal oscillation. J. Climate, 17, 4109-4134. 